\title{
La profundización de la pobreza en El Salvador en 1989-1990: aproximación desde la metodología de la deuda social
}

\author{
Carlos Acevedo, Edgar Flores y Rolando Arévalo
}

\section{Introducción}

En julio de 1989, al mes de haber asumido el poder Ejecutivo, la gestión de ARENA anunció la puesta en vigencia de un "Plan de Desarrollo Económico y Social" para el quinquenio 1989-1994, cuyos dos "objetivos globales" principales serian: 1) "crear las condiciones para alcanzar un crecimiento económico robusto y sostenido"; y 2) "elevar el bienestar y calidad de vida de toda la población, especialmente la que vive en extrema pobreza"1.

Operativamente, el Plan se dividia en dos vertientes principales, el Plan de Desarrollo Económico y el Plan de Desarrollo Social. A su vez, el Plan de Desarrollo Económico contemplaba dos "grandes líneas de acción: la primera línea de acción incluye en el plazo inmediato un programa de estabilización, el que comprende el periodo junio de 1989 a diciembre de 1990"2. La segunda línea de acción consistiría en la "reorientación de la economía a través de una readecuación integral de las estructuras, y el fortalecimiento de los mecanismos que alimenten el potencial competitivo e innovador de las fuerzas económicas"s. Esta segunda etapa se extendería a lo largo del periodo 1990-1994.

Por su parte, el Plan de Desarrollo Social comprendia también una estrategia de corto plazo y una estrategia de mediano plazo. La estrategia de corto plazo "involucra la definición y ejecución de políticas, 
programas y proyectos de naturaleza compensatoria, para amortiguar los efectos negativos de los programas de establlización y reorientación económica sobre los estratos poblacionales de menores recursos, tanto en el área metropolitana de San Salvador como al interior del pals ${ }^{m 4}$. La estrategia social de mediano plazo "incluye la formulación de planes sociales sectoriales, cuyo propósito fundamental es sentar las bases para un desarrollo social sostenido en el tiempo"s.

El Plan de Desarrollo Económico y Social 1989-1994 se presentaba, pues, como un programa de estabilización de los principales desequilibrios macroeconómicos de corto plazo, y como un programa de ajuste estructural orientado a reformar el aparato productivo en el mediano y largo plazo. Las políticas de estabilización corresponderlan a la primera etapa del Plan, sobre la cual se implementarla la etapa de "reorientación económica", consistente en la puesta en marcha de "un conjunto de reformas estructurales de mediano y largo plazo". Dado el sesgo recesivo de varias de las medidas de estabilización contenidas en el Plan, el propio gobierno dispuso acompanarlas de un programa social compensatorio en beneficio de "los más pobres de los pobres" que permitiera amortiguar el impacto del ajuste sobre estos sectores. En su diagnóstico de la situación de las necesidades básicas en el país, el Plan puntualizaba que "El Salvador ha sido un pais que históricamente ha tenido dificultades para satisfacer sus requerimientos alimenticios, porque la producción intema de alimentos ha sido insuficiente para cubrir las necesidades de la creciente poblacionn" Según el Plan, en 1989 la disponibilidad física per cápita de alimentos era un 20 por ciento inferior a la de $1978^{\circ}$. A su vez, esa limitada disponibilidad alimentaria se reflejaria dramáticamente en las condiciones nutricionales de la población. De acuerdo al diagnóstico del Plan, en 1989 habia en EI Salvador $\mathbf{4 3 0}$ mil ninos menores de 5 anos (47 por ciento sobre el total de ninos menores de esa edad) que padecian algún grado de desnutrición, de los cuales 135 mil presentaban desnutrición severa o moderada. Asimismo, el Plan citaba que el Primer Censo Nacional de Talla de Escolares, realizado en 1988, mostró que casi el 30 por ciento de los ninos de primer grado presentaban retardo en talla, cifra que hacia de El Salvador el país con más alta prevalencia de desnutrición en el área centroamericana. En algunas zonas geográficas del pais, el retardo de talla alcanzó niveles de entre 50 y 75 por ciento 9 .

No se puede, pues, negar que el Plan de Desarrollo Económico y Social posee una conciencia bastante explicita de la gravedad de las deficiencias prevalecientes en El Salvador en materia de satisfacción de necesidades básicas. El problema estriba en la difícil compatibilidad entre la lógica del modelo económico que el Plan propone y la satis- 
facción efectiva de las necesidades básicas de los sectores soclales más vulnerables. A este respocto, resulta significativo que, entre las primeras medidas que entraron en vigencia en julio de 1989, como parte de la estrategia económica de corto plazo, figuraba una liberalización casi general de precios que, aunque según el Plan no abarcaba a los productos de la canasta básica, de hecho deterioró considerablemente el poder adquisitivo de los sectores de menores ingresos.

Al cabo de dos anos de gestión de ARENA, y cuando la etapa de estabilización ya debió haber sido cumplida de acuerdo al cronograma original del Plan, esa situación ha empeorado sensiblemente. No obstante que el gobiemo se jacta de un crecimiento real del PIB del orden del 3.4 por ciento durante $1990^{10}$, los ingresos reales de los sectores sociales mayoritarios han experimentado un notable deterioro. Como resultado de ello, la satisfacción de las necesidades básicas de los grupos de población que viven en situación de pobreza y de pobreza extrema se ha tornado aún más crítica, al tiempo que ha aumentado sensiblemente la extensión de la pobreza.

De cara a esta situación, nuestro propósito en el presente trabajo consiste, precisamente, en evaluar el deterioro experimentado durante el primer ano de gestión económica de ARENA por la satisfacción de las necesidades básicas de los estratos poblacionales que viven en situación de pobreza.

Es necesario advertir que la investigación de esta cuestión enfrenta un problema estadistico de consideración, a saber, la carencia de suficiente evidencia empirica, expresada en indicadores socio-económicos agregados, sobre la evolución de la satisfacción de las necesidades básicas durante el periodo considerado. Por necesidades básicas entendemos fundamentalmente la alimentación, vivienda, salud y educación, las cuales habria que medir a través de ciertos indices principales, por ejemplo, de desnutrición, mortalidad infantil, etc., para el caso de la salud; analfabetismo, para la educación; déficit de viviendas, etc. Sin embargo, no se dispone todavia de cifras oficiales actualizadas de todos estos indicadores, que cubran el periodo considerado. Las Encuestas de Hogares de Propósitos Múltiples ofrecen varios datos valiosos para las áreas de vivienda y educación pero no para las de alimentación y salud, además de que cubren únicamente las zonas urbanas del pais, dejando por fuera a toda la población rural, que es presumiblemente donde la situación de pobreza y extrema pobreza está más difundida y donde la satisfacción de las necesidades básicas es más deficiente. Dicho sea de paso, la considerable debilidad de los mecanismos de control implementados por el gobierno para darle seguimiento a los indi- 
cadores sociales de bienestar es otra de las facetas del problema, en la medida que resta agilidad y oportunidad a la gestión social gubemamental encaminada a amortiguar el impacto de las medidas de estabilización sobre los sectores sociales más vulnerables".

En razón de la dificultad apuntada, hemos optado metodológicamente por efectuar el análisis en un doble momento: el primer momento consiste en la cuantificación de una canasta básica de bienes y servicios, de carácter normativo para el área urbana, que nos ofrezca un parámetro de referencia para evaluar el deterioro de las necesidades básicas a lo largo del primer ano de gestión de ARENA.

En un segundo momento, intentaremos cuantificar, mediante la metodología de la deuda social desarrollada por PREALC, la situación de pobreza estructural de la cual arranca el programa de estabilización económica, y la magnitud en que esa pobreza se ha profundizado durante el periodo 1989-1990. Consideramos que la aplicación de la metodologia de la deuda social al diagnóstico de la situación de pobreza histórica acumulada a la altura de 1990, permite una estimación preliminar de los recursos necesarios para superar la pobreza, al tiempo que ofrece un parámetro para medir, en ulteriores investigaciones, la eficacia de los programas compensatorios. Debido también a las mismas limitaciones de información estadística, ceniremos la mayor parte de nuestro análisis a la situación de la pobreza en el área urbana, a partir de los datos que ofrecen las Encuestas de Hogares de Propósitos Múltiples de 1989 y 1990, y de los índices de precios medios al por menor de los bienes y servicios de la canasta básica, publicados por MIPLAN.

\section{Evoluclón de la canasta básica de blenes y serviclos (junlo 1989-novlembre 1990)}

\subsection{Determinación de una canasta-patrón}

El propósito de este apartado es determinar una canasta normativa de bienes y servicios que permita seguir la evolución de las necesidades básicas de los sectores poblacionales ubicados por debajo de la línea de pobreza, durante el período comprendido entre junio de 1989 y noviembre de 1990. Esta canasta-patrón tiene dos componentes:

a) la canasta básica de alimentos, que la Secretaría Ejecutiva de la Comisión Nacional de Alimentación y Nutrición (SECONAN) define como el "conjunto de productos básicos que conforman la dieta usual de una población, en cantidades suficientes para cubrir adecuadamente, por to menos las necesidades energéticas de cada individuo"12, calculada en nuestro caso para una familia salvadorena pro- 
medio del área urbana; y

b) la canasta ampliada de bienes y servicios, la aual anade a la canasta alimentaria otro tipo de bienes y servicios imprescindibles para satisfacer otras necesidades básicas (vivienda, educación, vestuario, etc.).

Para el cálculo de la canasta básica alimentaria, hemos adoptado la estructura que utiliza MIPLAN, el cual estima que los requerimientos nutricionales mínimos que en promedio necesita diariamente una persona para reproducirse materialmente, trabajar, estudiar o recrearse en optimas condiciones, son 2,160 calorías y 46 gramos de proteínas, según los estudios realizados en 1983 por SECONAN.

Para el componente de la canasta ampliada, nos hemos apoyado en la estructura utilizada por Froilán Fernández en su trabajo Determinación del consumo mínimo en El Salvador, preparado en 1979 para el Departamento de Planificación del Ministerio de Trabajo y Previsión Social $^{13}$

\subsection{Evoluclón de la canasta básıca alimentarla}

Entre un conjunto de seis dietas diferentes propuestas por SECONAN, MIPLAN escoge una que cumple con las 2,160 calorías prescritas, y que considera se adecúa mejor al área urbana del país. El cuadro $\mathrm{N}^{2} 1$ presenta la estructura de dicha dieta.

\section{Cuadro № 1}

Dleta báslca urbana

\begin{tabular}{clc}
\hline Alimentos & $\begin{array}{c}\text { Granos } \\
\text { Dia/persona }\end{array}$ \\
\hline 1. Maiz & 173 \\
2. Frijol & 56 \\
3. Arroz & 65 \\
4. Azúcar & 69 \\
5. Huevos & 55 \\
6. Leche fluida & 106 \\
7. Carnes & 85 \\
8. Grasas & 36 \\
9. Verduras & 127 \\
10. Frutas & 157 \\
11. Pan francés & 40 \\
12. Sal & 10 \\
\hline
\end{tabular}

Fuente: MIPLAN. La canasta básica de alimentos. 1979-1989. 
En base a la estructura de alimentos del Cuadro $N^{2} 1$, cuantificada a los precios medios por menor de MIPLAN, estimamos el costo mensual de la canasta básica alimentaria. Asumimos una familia ubana promedio de 4.54 miembros, según los estimados de la Encuesta de Hogares de Propósitos Múltiples de 1989. En los cuadros 2, 3 y 4 presentamos el desglose de la canasta básica alimentaria para junio de 1989, y junio y noviembre de 1990, respectivamente. De acuerdo a dichos cuadros, el costo mensual de la canasta básica de alimentos para una familia urbana promedio en junio de 1989 era de 734.12 colones; a junio de 1990, dicho costo se habia incrementado a 825.37 colones (una diferencia de 91.25 colones); y a noviembre de 1990 , ascendla a 845.80 colones.

\subsection{Evolución de la canasta ampllada de blenes y serviclos}

Además de los alimentos, la satisfacción de las necesidades básicas implica un consumo mínimo en otros rubros, como lo son la vivienda, vestuario y varios servicios elementales: agua potable, energia, servicios higiénicos, salud, transporte, educación, etc. ${ }^{14}$ La adición de estos bienes y servicios a la canasta básica alimentaria constituye la llamada "canasta ampliada", para cuya estimación, siguiendo a Froilán Fernández, consideramos tres rubros principales de bienes y servicios: vestuario, vivienda y mobiliario, y misceláneos.

\subsubsection{Consumo nomatlvo de vestuarlo}

En su oportunidad, Froilán Fernández estableció los estándares de consumo (consumo normativo) de vestuario, a partir del consumo en que incurrlan las familias de estratos medios, de acuerdo a la Encuesta Nacional de Presupuestos Familiares (1976-1977), y de un hogar-tipo salvadoreno constituido por 5 personas, distribuidas asl:
2 adultos de 20 a 64 años
0.2 personas mayores de 64 anos de edad
0.8 ninos de 0 a 4 anos de edad
1.4 niños de 5 a 14 anos de edad
0.6 adolescentes de 15 a 19 anos de edad

Dado que la estructura por sexo de la población muestra una división en partes iguales (50 por ciento de cada sexo), el promedio de personas por hogar en cada grupo sexo-edad presentarla la estructura del Cuadro N 5. 


\section{Cuadro № 2 \\ Canasta básica de allmentos \\ Junlo / 89}

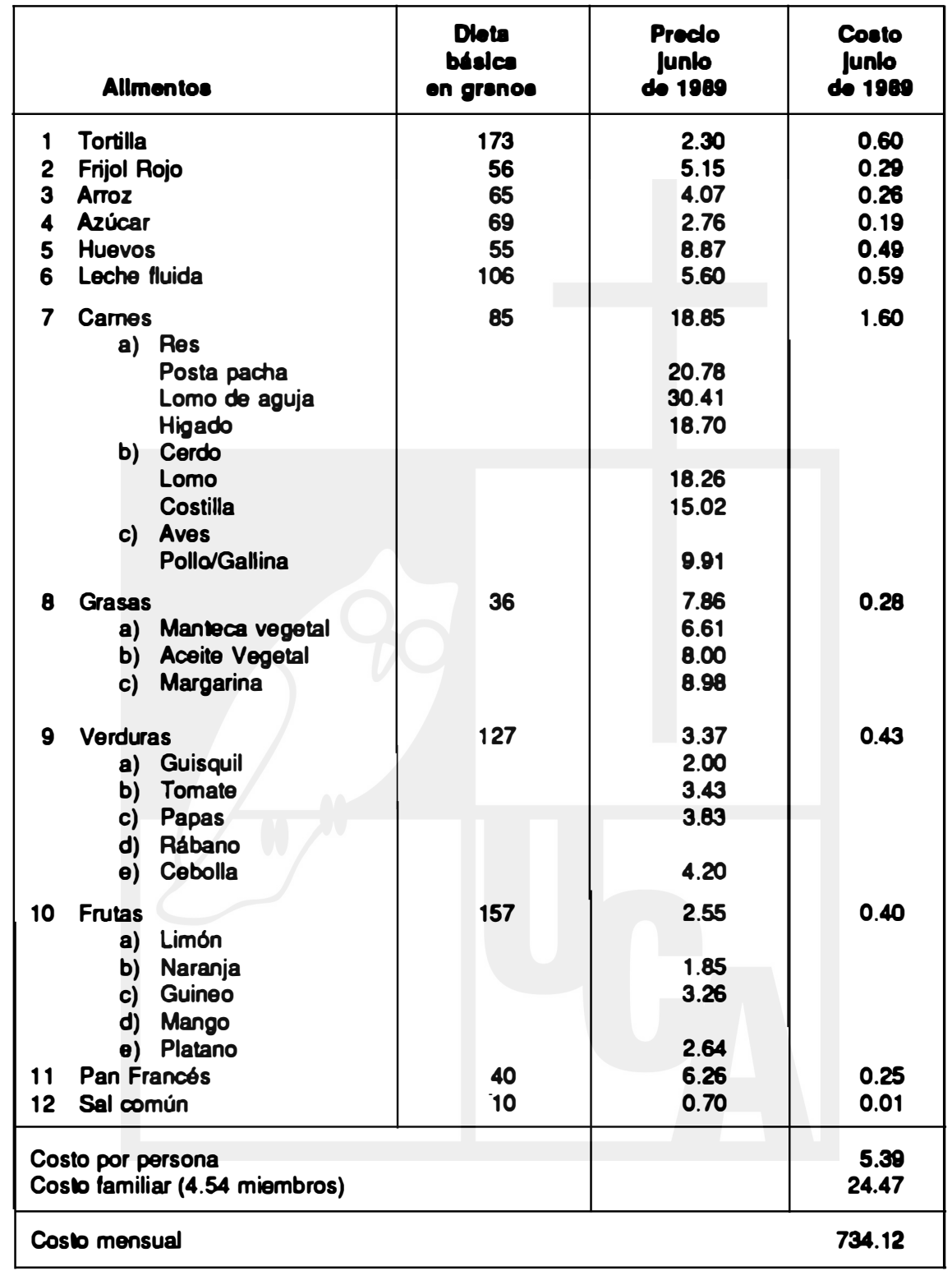

Fuente: Elaborado en base a los Precios Medios al por menor de DIGESTYC. 


\section{Cuadro No 3 \\ Canasta básica de allmentos \\ Junlo / 90}

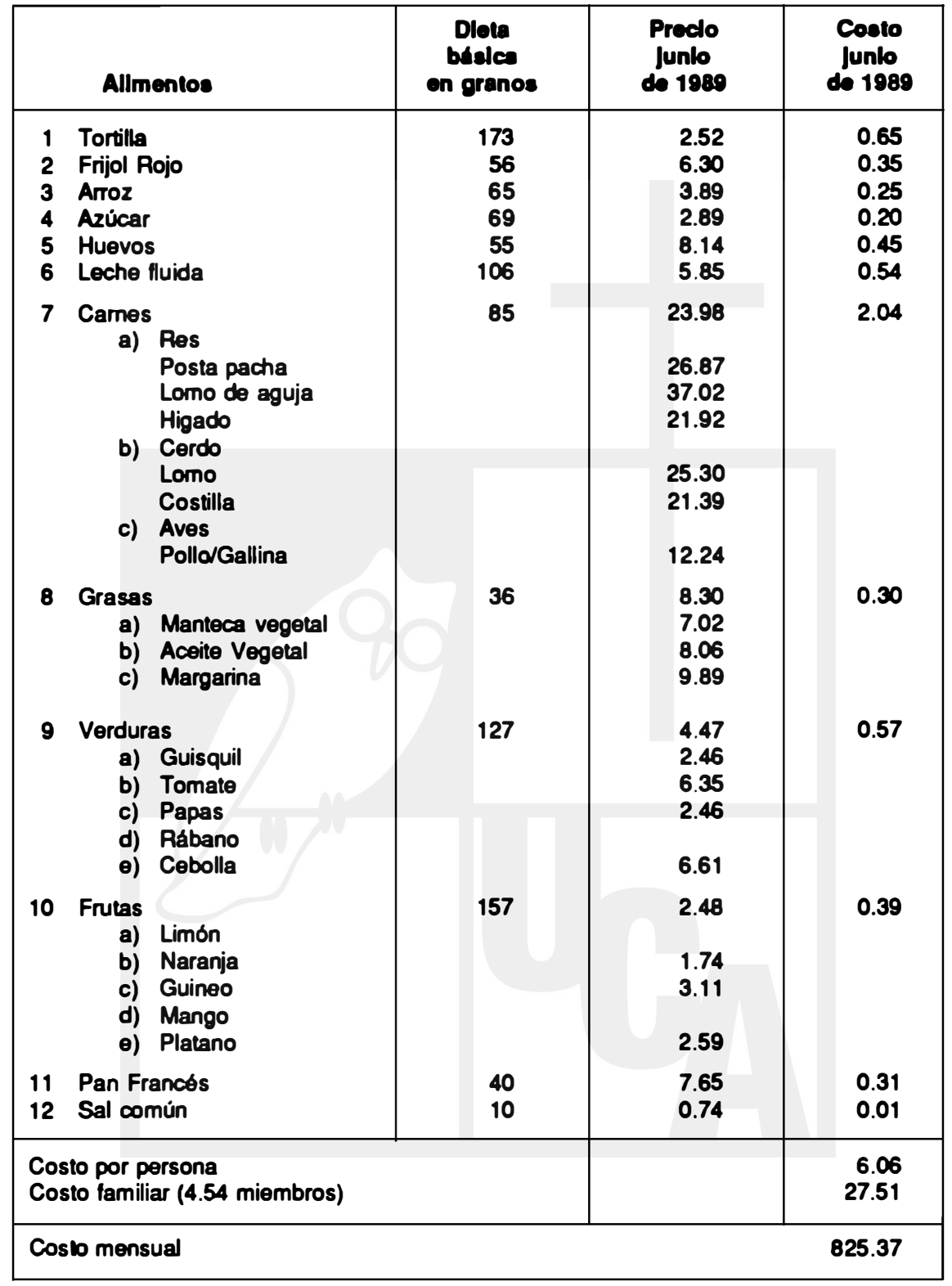

Fuente: Elaborado en base a los Precios Medios al por menor de DIGESTYC. 


\section{Cuadro Ne 4 \\ Canasta bislca de allmentos \\ Nov. 190}

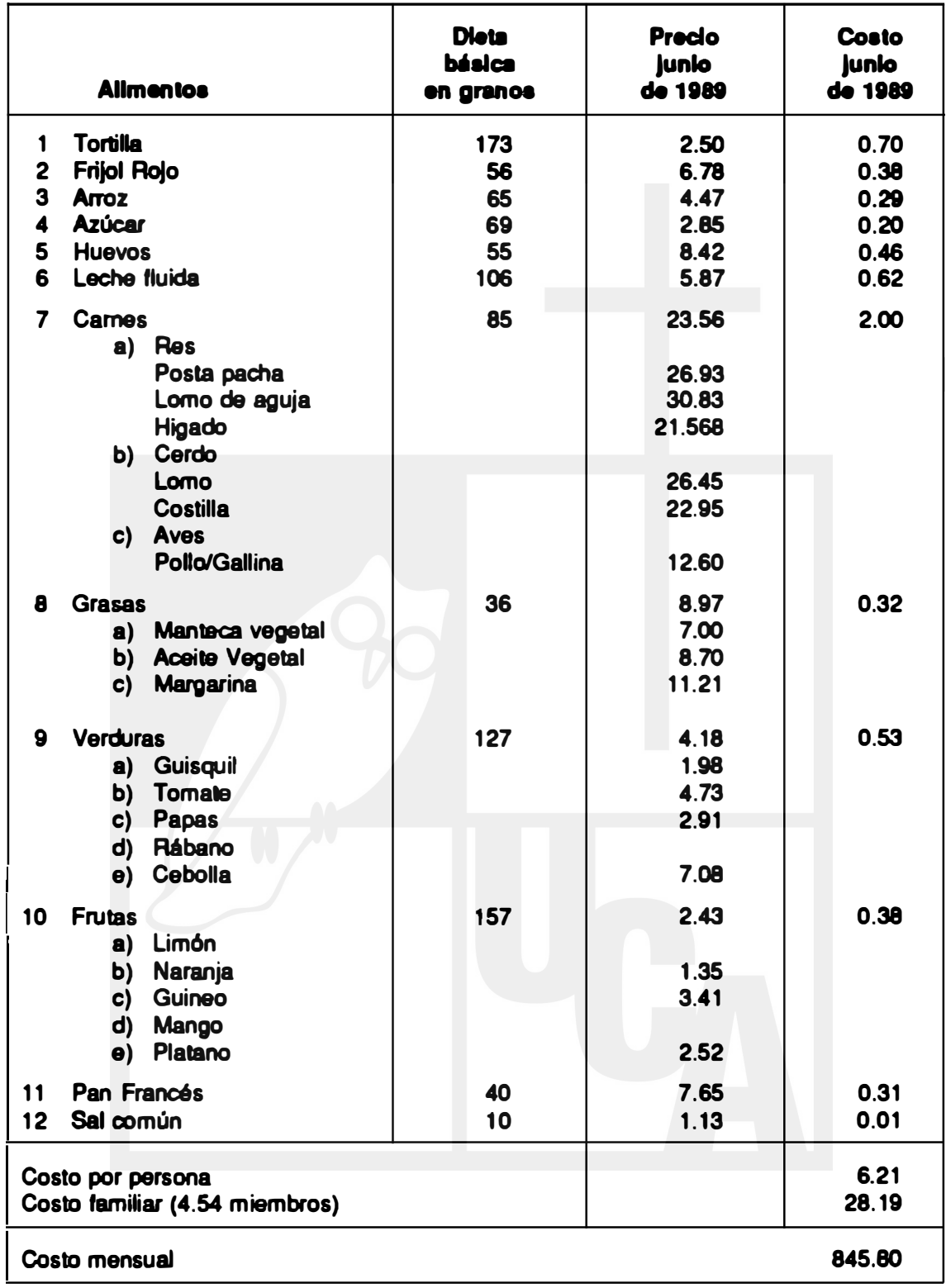

Fuente: Elaborado en base a los Precios Medios al por menor de DIGESTYC. 


\section{Cuadro N 5}

\section{Promedio de personas por edad y sexo}

(Para un hogar tipo salvadoreno)

\begin{tabular}{cccc}
\hline Edad & Personas & Hombres & Mujeres \\
\hline Total & 5.0 & 2.5 & 2.5 \\
0 a 4 & 0.8 & 0.4 & 0.4 \\
5 a 14 & 1.4 & 0.7 & 0.7 \\
15 a 19 & 0.6 & 0.3 & 0.3 \\
20 a 64 & 2.0 & 1.1 & 1.0 \\
65 y más & 0.2 & 0.1 & 0.1 \\
\hline
\end{tabular}

Fuente: Proyecciones de población MIPLAN-DIGES (a junio de 1979)

Si, a partir del Cuadro $N^{2} 5$, asumimos que los 5 miembros de cada familia tipo se dividen en partes iguales según sexo (2.5 hombres y 2.5 mujeres), y, a su vez, dividimos ambos grupos según un criterio de edad (mayores y menores de 15 anos), obtenemos la composición familiar siguiente:

\begin{tabular}{ll} 
Hombres & 1.4 \\
Mujeres & 1.4 \\
Ninos & 1.1 \\
Ninas & 1.1 \\
\hline Total & 5.0
\end{tabular}

A partir de la composición familiar por edad y sexo arriba senalada, y de la estructura de consumo de vestuario que se desglosa en el Cuadro $N^{2} 6$, calculamos el costo del consumo normativo de vestuario, actualizado para el perlodo 1989-1990, multiplicando el consumo anual de prendas de hombres, mujeres y ninos por cada uno de los factores anteriores y por los precios por unidad de las prendas respectivas. Suponemos que la estructura poblacional del Cuadro $N^{2} 5$ no se ha alterado significativamente; y que tampoco han variado sustancialmente los patrones de consumo de vestuario estimados por Froilán Fernández. Asl obtenemos el costo normativo anual y mensual por concepto de vestuario, que se presenta en el Cuadro $N^{2} 7^{15}$.

De acuerdo a las estimaciones del Cuadro № 7, el costo del componente de vestuario de la canasta ampliada se habrla incrementado de 197.11 colones mensuales en junio de 1989, a 223.16 colones mensuales en junio de 1990, y a 255.56 colones mensuales en noviembre de 1990. 


\section{Cuadro N 6}

\section{Costo normativo minimo de la canasta básica de vestuarlo}

\begin{tabular}{|c|c|c|c|c|c|c|c|}
\hline Articules & $\begin{array}{l}\text { Compras } \\
\text { anuales }\end{array}$ & $\begin{array}{l}\text { Precio X } \\
\text { unided } \\
\text { Junteg }\end{array}$ & $\begin{array}{l}\text { Coolo } \\
\text { Junl-89 }\end{array}$ & $\begin{array}{l}\text { Precto } x \\
\text { unidad } \\
\text { junt-80 }\end{array}$ & $\begin{array}{l}\text { coses } \\
\text { junteo }\end{array}$ & $\begin{array}{l}\text { Predo } X \\
\text { unked } \\
\text { Nov. } 10\end{array}$ & $\begin{array}{l}\text { Costo } \\
\text { Nov. } 80\end{array}$ \\
\hline \multicolumn{8}{|l|}{$\begin{array}{l}\text { Hombres adullos } \\
15 \text { anos y mis }\end{array}$} \\
\hline $\begin{array}{l}\text { Calzoncllos } \\
\text { Calcollnes } \\
\text { Zapalos } \\
\text { Pantalones } \\
\text { Canlsas } \\
\text { Camiselas }\end{array}$ & $\begin{array}{l}3 \\
3 \\
2 \\
3 \\
3 \\
2\end{array}$ & $\begin{array}{l}13.41 \\
10.36 \\
65.00 \\
70.00 \\
45.00 \\
15.43\end{array}$ & $\begin{array}{r}40.23 \\
31.08 \\
130.00 \\
210.00 \\
135.00 \\
15.43\end{array}$ & $\begin{array}{l}17.20 \\
10.85 \\
72.00 \\
75.00 \\
52.00 \\
20.45\end{array}$ & $\begin{array}{r}51.84 \\
32.65 \\
144.00 \\
225.00 \\
108.00 \\
40.80\end{array}$ & $\begin{array}{l}16.73 \\
10.60 \\
78.00 \\
65.00 \\
60.00 \\
23.81\end{array}$ & $\begin{array}{r}50.19 \\
32.07 \\
156.00 \\
255.00 \\
180.00 \\
47.22\end{array}$ \\
\hline Tolal & & & 561.74 & & 600.59 & & 720.48 \\
\hline \multicolumn{8}{|l|}{$\begin{array}{l}\text { Mujeres } \\
\text { mayores } \\
15 \text { anos y mas }\end{array}$} \\
\hline $\begin{array}{l}\text { Bloomer } \\
\text { Brassleres } \\
\text { Zapalos } \\
\text { Blusas } \\
\text { Vestlos } \\
\text { Fustanes } \\
\text { Pantalones } \\
\text { Carleras } \\
\text { Delantales } \\
\text { Medias } \\
\text { Ginas }\end{array}$ & $\begin{array}{l}3 \\
2 \\
2 \\
2 \\
2 \\
1 \\
1 \\
1 \\
1 \\
3 \\
1\end{array}$ & $\begin{array}{r}13.90 \\
20.92 \\
55.00 \\
35.00 \\
95.00 \\
20.00 \\
70.00 \\
60.00 \\
9.50 \\
6.71 \\
12.00\end{array}$ & $\begin{array}{r}41.97 \\
41.84 \\
110.00 \\
70.00 \\
190.00 \\
20.00 \\
70.00 \\
60.00 \\
9.50 \\
20.13 \\
12.00\end{array}$ & $\begin{array}{r}20.22 \\
24.27 \\
63.00 \\
42.50 \\
112.00 \\
25.00 \\
78.50 \\
63.00 \\
10.75 \\
8.28 \\
15.00\end{array}$ & $\begin{array}{r}60.66 \\
48.54 \\
128.00 \\
65.00 \\
224.00 \\
25.00 \\
78.50 \\
63.00 \\
10.75 \\
24.84 \\
15.00\end{array}$ & $\begin{array}{r}21.00 \\
26.70 \\
65.00 \\
60.34 \\
115.00 \\
20.00 \\
85.00 \\
65.00 \\
13.75 \\
9.87 \\
17.00\end{array}$ & $\begin{array}{r}63.00 \\
53.40 \\
130.00 \\
120.68 \\
230.00 \\
26.00 \\
85.00 \\
65.00 \\
13.75 \\
29.61 \\
17.00\end{array}$ \\
\hline Total & & & 645.44 & & 761.29 & & 033.44 \\
\hline \multicolumn{8}{|l|}{$\begin{array}{l}\text { Ninos monores } \\
\text { de } 15 \text { alos }\end{array}$} \\
\hline $\begin{array}{l}\text { Zapalos } \\
\text { Pantalones } \\
\text { Camisas } \\
\text { Calcelines } \\
\text { Camiselas } \\
\text { Calzoncillos }\end{array}$ & $\begin{array}{l}2 \\
3 \\
3 \\
3 \\
2 \\
3\end{array}$ & $\begin{array}{r}56.50 \\
50.00 \\
41.21 \\
6.00 \\
9.00 \\
4.00\end{array}$ & \begin{tabular}{r|}
113.00 \\
150.00 \\
123.83 \\
18.00 \\
18.00 \\
12.00
\end{tabular} & \begin{tabular}{r|}
53.78 \\
60.00 \\
35.65 \\
7.50 \\
8.40 \\
6.70
\end{tabular} & \begin{tabular}{r|}
107.56 \\
180.00 \\
106.95 \\
22.50 \\
16.60 \\
20.10
\end{tabular} & $\begin{array}{r}64.95 \\
68.00 \\
38.03 \\
8.50 \\
9.75 \\
9.61\end{array}$ & $\begin{array}{r}129.90 \\
204.00 \\
114.09 \\
25.50 \\
19.50 \\
28.83\end{array}$ \\
\hline Total & & & 434.63 & & 453.91 & & 521.82 \\
\hline \multicolumn{8}{|l|}{$\begin{array}{l}\text { Ninas menores } \\
\text { de } 15 \text { alos }\end{array}$} \\
\hline $\begin{array}{l}\text { Zapalos } \\
\text { Pantalones } \\
\text { Blusas } \\
\text { Calcelas } \\
\text { Vestldos } \\
\text { Bloomers }\end{array}$ & $\begin{array}{l}2 \\
1 \\
2 \\
3 \\
3 \\
3\end{array}$ & $\begin{array}{r}39.95 \\
55.00 \\
25.00 \\
6.00 \\
60.00 \\
4.75\end{array}$ & $\begin{array}{r}79.90 \\
55.00 \\
50.00 \\
18.00 \\
180.00 \\
14.25\end{array}$ & $\begin{array}{r}45.95 \\
63.00 \\
38.76 \\
8.40 \\
72.00 \\
6.80\end{array}$ & $\begin{array}{r}91.80 \\
63.00 \\
77.52 \\
25.20 \\
216.00 \\
20.40\end{array}$ & $\begin{array}{r}54.08 \\
72.00 \\
42.50 \\
9.75 \\
85.00 \\
7.15\end{array}$ & $\begin{array}{r}108.16 \\
72.00 \\
65.00 \\
29 . .25 \\
255.00 \\
21.45\end{array}$ \\
\hline Tolal & & & 397.15 & & 494.02 & & 570.88 \\
\hline
\end{tabular}




\section{Cuadro № 7 \\ Estimación del consumo normatlvo de vestuario en el área urbana de El Salvador en 1989-1990 \\ (En colones)}

\begin{tabular}{lccc}
\hline & Junio 1989 & Junio 1990 & Nov. 1990 \\
\hline Hombres & 714.08 & 763.47 & 915.87 \\
Mujeres & 820.43 & 967.75 & 1059.47 \\
Ninos & 434.11 & 453.36 & 521.19 \\
Ninas & 396.67 & 493.42 & 570.17 \\
\hline Total anual & $2,365.30$ & 2678.00 & 3066.70 \\
\hline Total mensual & 197.11 & 223.16 & 255.56 \\
\hline
\end{tabular}

\subsubsection{Consumo normativo de vivienda, moblliarlo y equipo del hogar}

Al igual que para el rubro de vestuario, para el de vivienda seguimos la estructura normativa propuesta por Froilán Femández, quien sehala que "el derecho a la vivienda digna y a los servicios de la misma es una necesidad y aspiración popular que merece ser tomada en cuenta y satisfecha"16.

El tipo de vivienda propuesta y que reúne las condiciones necesarias para albergar a una familia urbana promedio salvadorena es el siguiente: vivienda con 3 dormitorios, servicio higiénico, cocina, sala-comedor y áreas verdes, ya sea colectivas o individuales. En 1979, este estándar de vivienda correspondía a las casas tipo ED-3, con un área construida de $55 \mathrm{mts}^{2}$, edificadas por el Instituto de Vivienda Urbana (IVU).

En junio de 1989, de acuerdo a una investigación realizada en el Fondo Social para la Vivienda (FSV), el tipo de vivienda que reunfa esas características tenia un costo promedio de 36 mil colones, a un plazo de 20 anos y cuotas mensuales de 337.50 colones.

Según información obtenida en el FSV, entre abril de 1988 y diciembre de 1990, el límite de crédito financiable era de 40 mil colones. A junio de 1990, el tipo de vivienda arriba apuntado tenla un costo de 43,900 colones, a un plazo de 20 anos y cuotas mensuales de $\mathbf{4 7 2 . 8 0}$ colones. Es de senalar que viviendas de este tipo solamente se pueden encontrar en las zonas periféricas de San Salvador, como Apopa, Zacamil, Soyapango, etc.

\section{8}


En lo que se refiere a los servicios básicos de la vivienda, las investigaciones realizadas por Froilán Fernández sobre el consumo normativo de agua potable sehalan que la familia urbana promedio salvadoreha consume mensualmente $30 \mathrm{mts}^{3}$ de agua. En junio de 1989, el costo de $30 \mathrm{mts}^{3}$ de agua era 12 colones; en junio de 1990, el costo del mismo volumen se habia incrementado a 15.88 colones.

Para determinar el consumo de energía eléctrica, Froilán Fernández realizó investigaciones en hogares que dispusieran de refrigeradora, plancha, radio y televisor, además de los focos normales. Determinó que el consumo eléctrico promedio en ese tipo de hogares era de 110 KWH por mes.

\title{
Cuadro $N^{2} 8$
}

Estructura tarlifarla para el consumo doméstlco de energla eléctrica vigente en El Salvador en Junlo de 1989.

\author{
Tarifa No 1A (D) para servicio domestico \\ los Primeros .... 20KWH c/u a $c 0.141$ \\ los siguientes... 80KWH c/u a $₫ 0.166$ \\ los siguientes...100KWH c/u a $\$ 0.200$
}

Fuente: Comisión Ejecutiva Hidroeléctrica del Río Lempa.

Según el Acuerdo 485 del Organo Ejecutivo en el ramo de Economía, las tarifas de venta de energía eléctrica vigentes en junio de 1989 eran las del Cuadro $N^{2} 8^{17}$. Dicha tabla tarifaria estuvo vigente hasta el 1 de agosto de 1989. Por tanto, en junio de 1989, el costo de 110 KWH era de 18.26 colones.

\section{Cuadro $N^{2} 9$}

Estructura tarlfarla para el consumo doméstico de energla eléctrica vigente en El Salvador en Junlo de 1990.

Tarifa No. 1A (D) para servicio domestico

los primeros .... 40KWH c/u a $\$ 0.166$ los siguientes...160KWH c/u a $\$ 0.254$ los siguientes...300KWH c/u a $\$ 0.419$

Fuente: Comisión Ejecutiva Hidroeléctrica del Río Lempa. 
A partir de agosto de 1989, la tabla tarifaria vigente fue la que se presenta en el Cuadro $N^{2}$ 9. Por tanto, en junio de 1990, el costo de los $110 \mathrm{KWH}$ se habia incrementado a 24.42 colones.

Con respecto al gas propano, que es el combustible que se utiliza con más frecuencia en el área urbana del país, se estimo un consumo promedio mensual de 35 libras por familia, cuyo costo en junio de 1989 era de 22.95 colones, según los precios medios por menor de DIGESTYC. Para junio de 1990, el costo del tambo de 35 libras se había incrementado a 24.18 colones.

El consumo normativo en mobiliario y equipo básico del hogar, de acuerdo a la estructura de consumo elaborada por Froilán Femández, actualizada para 1989-1990 en base a los precios medios al por menor de DIGESTYC, se presenta en el Cuadro $N^{2} 10$. Es pertinente aclarar que en este rubro no están incluidos los gastos referentes a utensilios del hogar, los cuales representan aproximadamente un 6 por ciento del gasto en vivienda, mobiliario y equipo del hogar.

Al agregar los rubros anteriores, obtenemos el Cuadro $N^{2} 11$, el cual presenta la estructura de costos de la canasta ampliada por concepto de vivienda, mobiliario y equipo del hogar, actualizada a junio de 1989 , y a junio y noviembre de 1990.

\subsubsection{Consumo normatlvo en misceláneos}

En el rubro de misceláneos, Froilán Fernández incluye salud, educación y cultura, transporte y comunicaciones, aseo personal, reparación y mantenimiento de la vivienda y recreación y deportes. Para el cálculo del consumo normativo de misceláneos, seguimos en lo fundamental la estructura de consumo propuesta por Fernández, actualizada para 1989-1990 de acuerdo a los precios medios al por menor de DIGESTYC, según se presenta en el Cuadro № 12.

Una vez efectuados los cálculos anteriores, al agregar a la canasta básica alimentaria los costos de vestuario, vivienda y misceláneos, obtenemos el costo de la canasta ampliada de bienes y servicios básicos que se presenta en el Cuadro $\mathrm{N}^{2} 13$. Tal como se aprecia, entre junio de 1989 y junio de 1990, el costo de dicha canasta se incrementó de $1,891.95$ a 2,258.67 colones, esto es, experimentó un incremento del 19.4 por ciento. A nivel desagregado, el costo de sus componentes de alimentos, vestuario, vivienda y misceláneos se incrementó, respectivamente, en 12.4, 13.2, 36.6 y 13.2 por ciento. Si la comparación se efectúa entre junio de 1989 y noviembre de 1990, se aprecia un incremento del 27.1por ciento en el costo total de la canasta básica de bienes y servicios. En el mismo periodo, el costo de sus componentes de ali- 
Cuadro No. 10

Consumo normativo minimo en

Moblliarlo y equlpo básico del hogar

\begin{tabular}{|c|c|c|c|c|c|c|c|}
\hline \multirow[b]{2}{*}{ Artallas } & \multirow[b]{2}{*}{$\begin{array}{l}\text { Anos de } \\
\text { depre } \\
\text { ciación }\end{array}$} & \multicolumn{2}{|c|}{ Junio de 1809} & \multicolumn{2}{|c|}{ Junio de 1890} & \multicolumn{2}{|c|}{ Nov. 1980} \\
\hline & & $\begin{array}{l}\text { Precio } \\
\text { unitario }\end{array}$ & $\begin{array}{l}\text { Cosio } \\
p / 10 \\
\text { anos }\end{array}$ & $\begin{array}{l}\text { Precto } \\
\text { unitario }\end{array}$ & $\begin{array}{l}\text { Cosio p/ } \\
10 \text { anlos }\end{array}$ & $\begin{array}{l}\text { Preclo } \\
\text { unitasito }\end{array}$ & $\begin{array}{l}\text { Costo p/ } \\
10 \text { anos }\end{array}$ \\
\hline $\begin{array}{l}1 \text { Juego de sala tlpico } \\
1 \text { Juego de comedor con } \\
6 \text { Sillas (hierto y } \\
\text { (órmica) }\end{array}$ & $\begin{array}{r}5 \\
10\end{array}$ & $\begin{array}{r}1462.00 \\
694.91\end{array}$ & $\begin{array}{r}2924.00 \\
694.91\end{array}$ & $\begin{array}{r}1793.00 \\
803.70\end{array}$ & $\begin{array}{r}3586.00 \\
803.70\end{array}$ & $\begin{array}{r}1824.60 \\
853.23\end{array}$ & $\begin{array}{r}3649.20 \\
853.33\end{array}$ \\
\hline $\begin{array}{l}5 \text { Carnas semimatrimo- } \\
\text { nial Metálica sencilla }\end{array}$ & 7 & 2140.40 & 3057.00 & 2671.80 & 3816.85 & 2759.00 & 3941.41 \\
\hline $\begin{array}{l}1 \text { T.V. blanco y negro } \\
\text { de } 14 \text { pulgadas }\end{array}$ & 6 & 1707.73 & 2846.22 & 1698.50 & 2830.83 & 1692.00 & 2820.00 \\
\hline 1 Redio pequeno & 10 & 273.80 & 273.80 & 281.33 & 281.83 & 288.20 & 288.20 \\
\hline 1 Plancha eléctrica & 3 & 161.33 & 537.76 & 216.45 & 721.15 & 243.30 & 811,00 \\
\hline $\begin{array}{l}1 \text { Cocina de gas propano } \\
\text { dos quemadores sin horna }\end{array}$ & 5 & 683.92 & 1367.84 & 807.23 & 1814.48 & 1020.00 & 2040.00 \\
\hline 1 Relrigerador de 9 pies & 10 & 1045.10 & 1045.10 & 3236.23 & 3236.23 & 3432.25 & 3422.25 \\
\hline Total & & 8169.19 & 12737.34 & 11608.74 & 17091.05 & 12092.50 & 1815.4 \\
\hline Cosio tolal mensual & & & 132.78 & & 178.04 & & 185.57 \\
\hline
\end{tabular}

Fuente: Elaborado en base a los Precios medios al por Menor de DIGESTYC.

Cuadro № 11

Consumo normatlvo de vivienda, moblliarlo y serviclos báslcos en el área urbana de El Salvador en 1989-1990.

(En colones)

junio 89 junio 90 nov. 90

Mensualidad por la adquisición

de vivienda propia $\left(55 \mathrm{~m}^{2}\right)$

\begin{tabular}{lrrrr}
\hline & junio 89 & junio 90 & nov. 90 \\
\hline Mensualidad por la adquisición & & & \\
de vivienda propia $\left(55 \mathrm{~m}^{2}\right)$ & 337.50 & 472.80 & 540.00 \\
Pago de servicios de agua potable $\left(30 \mathrm{~m}^{3}\right)$ & 12.00 & 15.88 & 15.88 \\
Energía eléctrica (110KWH) & 18.26 & 24.42 & 24.42 \\
Gas propano para cocina 35 Ib & 22.95 & 24.18 & 28.58 \\
Mobiliario y equipo básico del hogar & 132.78 & 178.04 & 185.57 \\
\hline Total mensual & 523.49 & 715.32 & 793.95 \\
\hline
\end{tabular}

Fuente: Elaborado en base a los precios medios al por menor de DIGESTYC. 


\section{Cuadro N2 12}

\section{Consumo normativo minimo en miscelaneos}

\begin{tabular}{|c|c|c|c|c|c|c|c|c|c|}
\hline & \multicolumn{3}{|c|}{ 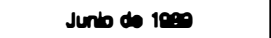 } & \multicolumn{3}{|c|}{ סיסו טג לחע } & \multicolumn{3}{|c|}{ 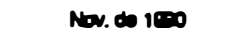 } \\
\hline & $\begin{array}{l}\text { Cono } \\
\text { unte- } \\
\text { to }\end{array}$ & Cocol & $\begin{array}{l}\text { cono } \\
\operatorname{man} \text { - } \\
\text { and }\end{array}$ & $\begin{array}{c}\text { Cocto } \\
\text { unte } \\
\text { to }\end{array}$ & $\begin{array}{l}\text { Codo } \\
\text { anued }\end{array}$ & $\min _{\operatorname{con}}^{\cos }$ & $\begin{array}{c}\text { come } \\
\text { unito }\end{array}$ & 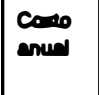 & Cont \\
\hline \multicolumn{10}{|l|}{ Senvidos protesbonale: } \\
\hline 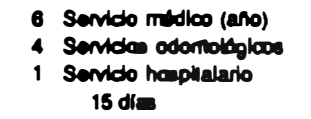 & $\begin{array}{l}29.50 \\
21.67 \\
43.30\end{array}$ & $\begin{array}{r}177.00 \\
63.60 \\
640.05\end{array}$ & $\begin{array}{r}14.75 \\
722 \\
54.18\end{array}$ & $\begin{array}{l}37.00 \\
23.33 \\
30.67\end{array}$ & $\begin{array}{r}202.00 \\
03.12 \\
550.06\end{array}$ & $\begin{array}{r}18.6 \\
7.78 \\
46.84\end{array}$ & $\begin{array}{l}39.13 \\
24.44 \\
37.00\end{array}$ & $\begin{array}{r}203.70 \\
07.70 \\
65.00\end{array}$ & $\begin{array}{r}10.07 \\
8.16 \\
40.26\end{array}$ \\
\hline Toen & & & 76.14 & & & 72.11 & & & 73.40 \\
\hline \multicolumn{10}{|l|}{ Medicine general: } \\
\hline $\begin{array}{l}\text { Vhemina con minerales } \\
40 \text { grease } \\
\text { Sal Andrews (50 soores) } \\
\text { Antblations } 4 \text { irascos }\end{array}$ & $\begin{array}{l}0.35 \\
0.41 \\
2.43\end{array}$ & $\begin{array}{r}14.00 \\
20.50 \\
0.72\end{array}$ & $\begin{array}{l}1.17 \\
1.71 \\
0.81\end{array}$ & $\begin{array}{l}0.37 \\
0.45 \\
8.03\end{array}$ & $\begin{array}{l}14.60 \\
22.50 \\
23.12\end{array}$ & $\begin{array}{l}1.23 \\
1.60 \\
2.60\end{array}$ & $\begin{array}{l}0.40 \\
0.40 \\
0.60\end{array}$ & $\begin{array}{l}18.00 \\
24.60 \\
38.24\end{array}$ & $\begin{array}{l}1.33 \\
2.04 \\
3.10\end{array}$ \\
\hline Tore & & & 3.60 & & & 6.70 & & & 0.60 \\
\hline \multicolumn{10}{|l|}{ Instrucrion y cultura: } \\
\hline $\begin{aligned} 16 & \text { Lbros do texto } \\
2 & \text { Papos de encentanza } \\
16 & \text { Cuadomos cacolare } \\
365 & \text { Peribdlosa }\end{aligned}$ & $\begin{array}{r}70.00 \\
09.28 \\
5.42 \\
0.72\end{array}$ & $\begin{array}{r}1120.00 \\
1170.38 \\
80.72 \\
282.60\end{array}$ & $\begin{array}{r}\infty 3.33 \\
18.28 \\
7.23 \\
21.00\end{array}$ & \begin{tabular}{r|}
87.50 \\
110.68 \\
6.51 \\
1.02
\end{tabular} & $\begin{array}{l}1400.00 \\
1327.02 \\
104.16 \\
372.30\end{array}$ & $\begin{array}{r}116.87 \\
110.68 \\
6.68 \\
31.03\end{array}$ & $\begin{array}{r}85.00 \\
117.76 \\
6.75 \\
1.02\end{array}$ & $\begin{array}{r}1390.00 \\
1413.12 \\
108.00 \\
37230\end{array}$ & $\begin{array}{r}113.30 \\
117.76 \\
0.00 \\
31.00\end{array}$ \\
\hline Total & & & 220.74 & & & 287.00 & & & 271.12 \\
\hline \multicolumn{10}{|l|}{ Culdedos porsonel- } \\
\hline 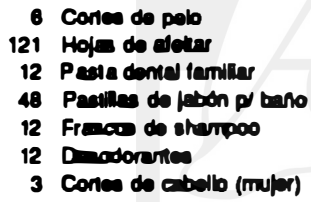 & \begin{tabular}{r|}
6.14 \\
0.70 \\
8.38 \\
2.40 \\
10.25 \\
16.75 \\
6.63
\end{tabular} & $\begin{array}{r}40.84 \\
84.70 \\
100.32 \\
115.20 \\
231.39 \\
201.00 \\
20.40\end{array}$ & $\begin{array}{r}4.07 \\
7.08 \\
8.30 \\
0.60 \\
1020 \\
18.75 \\
1.71\end{array}$ & \begin{tabular}{r|}
0.06 \\
1.08 \\
8.50 \\
2.13 \\
2020 \\
1328 \\
7.60
\end{tabular} & $\begin{array}{r}50.70 \\
130.80 \\
10272 \\
86.20 \\
242.78 \\
106.12 \\
22.50\end{array}$ & $\begin{array}{r}4.90 \\
10.60 \\
6.50 \\
7.10 \\
2020 \\
1620 \\
1.80\end{array}$ & $\begin{array}{r}0.75 \\
1.30 \\
0.22 \\
2.30 \\
18.00 \\
22.81 \\
7.20\end{array}$ & $\begin{array}{r}60.60 \\
167.30 \\
110.64 \\
2020 \\
220.6 \\
273.72 \\
20.40\end{array}$ & $\begin{array}{r}4.40 \\
13.11 \\
0.22 \\
7.77 \\
18.00 \\
22.81 \\
1.00\end{array}$ \\
\hline Total & & & ex.er & & & $\infty .60$ & & & 78.64 \\
\hline \multicolumn{10}{|l|}{ Traneponte y comuntendone } \\
\hline 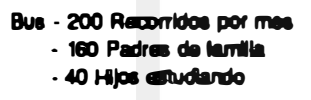 & 0.35 & & 70.00 & 0.40 & & $\infty 0.00$ & 0.40 & & 60.00 \\
\hline Costo totel menaud & & & 437.40 & & & 404.62 & & & 608.87 \\
\hline
\end{tabular}

Fuente: Elaborado en base a los precios medios el por menor de DIGESTYC. 
mentos, vestuario, vivienda y misceláneos experimentó, respectivamente, incrementos del 15.2, 29.7, 51.7 y 16.4 por ciento.

Cuadro № 13.

Consumo normatlvo minimo mensual de una familla urbana tlpo en EI Salvador en 1989-1990.

(En colones)

\begin{tabular}{lccc}
\hline & Junio 89 & Junio 90 & Nov. 90 \\
\hline Alimentación & 734.12 & 825.37 & 845.80 \\
Vestuario & 197.11 & 223.16 & 255.56 \\
Vivienda & 523.49 & 715.32 & 793.95 \\
Miscelaneos & 437.23 & 494.82 & 508.87 \\
\hline Total mensual & 1891.95 & 2258.67 & 2404.18
\end{tabular}

Fuente: Elaborado en base a los precios medios al por menor de DIGESTYC.

3. Cálculo de la pobreza en El Salvador a partir de la metodologla de la deuda soclal de PREALC

La canasta básica de bienes y servicios constituye un instrumento útil no sólo para medir genéricamente el grado de satisfacción de las necesidades básicas de un determinado conglomerado social, sino sobre todo para determinar los niveles de pobreza y de pobreza extrema (o pobreza crítica) prevalecientes en una sociedad determinada, en la medida que ofrece un parámetro de referencia de lo que serian los consumos mínimos de supervivencia (canasta básica alimentaria) y de satisfacción de otras necesidades básicas (canasta ampliada) en dicha sociedad. Convencionalmente, se acepta que la canasta básica alimentaria ofrece un referente para determinar la línea de pobreza extrema, pobreza crítica o indigencia; mientras que la canasta ampliada sería el referente para determinar el nivel de la pobreza relativa y de la linea de pobreza ${ }^{18}$. Por tanto, la evolución de la canasta básica de bienes y servicios a lo largo de la etapa de estabilización económica de la gestión de ARENA (1989-1990) constituye un indicador de la evolución de la pobreza durante dicho periodo.

SI la canasta básica que hemos cuantificado en al apartado anterior se coteja $\infty$ n los datos del cuadro $N^{2} 14$, el cual presenta la distribución por deciles del ingreso familiar mensual de los hogares ubanos del país para el periodo 1988-1990, obtendremos los porcentajes de familias urbanos en situación extrema pobreza y de pobreza relativa. Asl, 
tomando en cuenta que el costo de la canasta básica de alimentos a junio de 1989 era de 734.12 colones (Cuadro $N^{2} 13$ ), ello significa que al menos un 35 por ciento de la población urbana se encontraba en situación de extrema pobreza, al no poder cubrir con sus ingresos mensuales sus necesidades básicas de alimentación. Adoptando la metodología del Banco Mundial y de la CEPAL para el cálculo de la canasta ampliada de bienes y servicios básicos, que ambos organismos estiman en el doble de la canasta básica de alimentos ${ }^{10}$, resultaría que, en ese mismo mes, por lo menos el 68 por ciento de la población urbana estaba situada por debajo de la línea de pobreza, esto es, no podía cubrir con sus ingresos la canasta ampliada de bienes y servicios.

Cabe sefalar, sin embargo, que la estimación del costo de la canasta ampliada como equivalente al doble del costo de la canasta básica alimentaria no refleja, al menos en el caso de los hogares urbanos de El Salvador, el costo real de la canasta ampliada. Así, por ejemplo, de acuerdo a la metodología del Banco Mundial y de la CEPAL, el costo de la canasta ampliada en junio de 1989 debiera haber rondado en torno a 1468 colones, cuando, según los datos del Cuadro $N^{2} 13$, ascendió de hecho a 1891.95 colones. Análogamente, si el costo de la canasta básica alimentaria en junio de 1990 (825.37 colones) se multiplica por 2 para obtener un aproximado del costo de la canasta ampliada a esa fecha, éste debió ascender a 1650.74 colones; sin embargo, de hecho ascendió a 2258.67 colones. En otras palabras, el cálculo del costo de la canasta ampliada como equivalente al doble del costo de la canasta básica alimentaria conduce a una sensible subestimación de su magnitud real en el caso de los hogares urbanos salvadorehos para el periodo 1989-1990. En consecuencia, ese modo de estimación de la canasta ampliada afecta también la estimación del nivel de la línea de pobreza y, consiguientemente, la magnitud de la pobreza relativa. Así, de acuerdo a los datos del Cuadro Ne 13, cotejados con el Cuadro № 14 por medio de extrapolación lineal, en 1989 el 78 por ciento de los hogares urbanos salvadorenos estaba por debajo de la línea de pobreza; en 1990, ese porcentaje se habia incrementado a 81 por ciento. Para los mismos anos, en cambio, los datos correspondientes que MIPLAN reconocia eran 55.2 y 63 por ciento, respectivamente ${ }^{20}$.

En lo que sigue, intentaremos estimar, a partir de la metodología de la deuda social desarrollada por PREALC, la magnitud en que la pobreza urbana se extendió en El Salvador entre 1989 y 1990, así como las dimensiones de la pobreza estructural a la altura de 1990. Para el cálculo del ingreso de necesidades básicas, que la metodología de PREALC exige como una de las variables necesarias para estimar la intensidad de la pobreza, asumimos los costos de la canasta ampliada 


\section{Cuadro Ne 14 \\ Dlstribuclón del Ingreso famillar mensual de los hogares urbanos, por déclles \\ Ano de 1988 a 1990}

\begin{tabular}{l|r|r|r|r|r|r|r|r|r}
\hline & \multicolumn{3}{|c|}{ Hogares } & \multicolumn{3}{c|}{ Ingreso promedio } & \multicolumn{3}{c}{$\begin{array}{c}\text { Porcentrie de } \\
\text { ingresos recibido }\end{array}$} \\
\cline { 2 - 10 } Déciles & 1988 & 1989 & 1990 & 1988 & 1989 & 1990 & 1988 & 1989 & 1990 \\
\hline Primero & 49,074 & 49,726 & 52,658 & 212.31 & 207.48 & 180.66 & 1.81 & 1.51 & 1.21 \\
Segundo & 49,074 & 49,726 & 52,658 & 438.45 & 424.95 & 408.29 & 3.74 & 3.08 & 2.73 \\
Tercero & 49,074 & 49,726 & 52,658 & 645.46 & 582.12 & 604.57 & 5.50 & 4.22 & 4.04 \\
Cuarto & 49,074 & 49,726 & 52,658 & 731.77 & 734.57 & 785.53 & 6.24 & 5.33 & 5.25 \\
Ouinto & 49,074 & 49,726 & 52,658 & 874.21 & 897.15 & 964.78 & 7.45 & 6.51 & 6.45 \\
Sexto & 49,074 & 49,726 & 52,658 & $1,060.98$ & $1,091.68$ & $1,166.08$ & 9.04 & 7.92 & 7.79 \\
Séptimo & 49,074 & 49,726 & 52,658 & $1,259.71$ & $1,359.77$ & $1,460.72$ & 10.74 & 9.87 & 9.76 \\
Octavo & 49,074 & 49,726 & 52,658 & $1,458.54$ & $1,701.41$ & $1,867.93$ & 12.52 & 12.35 & 12.48 \\
Noveno & 49,074 & 49,726 & 52,658 & $1,818.43$ & $2,314.22$ & $2,546.09$ & 15.50 & 16.79 & 17.01 \\
Decimo & 49,074 & 49,726 & 52,658 & $3,222.82$ & $4,467.20$ & $4,979.48$ & 27.48 & 32.43 & 33.28 \\
\hline
\end{tabular}

Fuente: Encuestas de Hogares de Propósitos Multiples/MIPLAN

que se presentan en el cuadro № 13, debido a que nos parece que se aproximan más al nivel de pobreza urbana realmente prevaleciente en El Salvador.

\subsection{Definición de la deuda soclal}

El proceso analítico que forjó la idea de la "deuda social" y la metodología para calcularla se remonta a $1983^{21}$, si bien el concepto estricto de "deuda social" fue pertilado sólo hasta $1987^{22}$ e instrumentalizado cuantitativamente hasta $1988^{23}$. El contexto histórico de ese trabajo analítico ha sido la crisis de la deuda externa en América Latina, y el propósito fundamental que ha movido a PREALC en dicha tarea ha sido desarrollar una metodología que permita cuantificar el enorme esfuerzo que la región ha desplegado para hacerle frente al pago de la deuda externa, y la desigual forma en que se han repartido los costos de la crisis.

En una primera aproximación al concepto, PREALC define la deuda social como "la cantidad de recursos necesarios para superar la pobreza y para alcanzar un grado de equidad distributiva socialmente aceptable"24. PREALC considera en situación de pobreza a "aquellos grupos familiares que no cuentan con un ingreso igual o mayor a la línea de pobreza"zs; por linea de pobreza entiende "la cantidad de recursos que requiere una familia para satisfacer sus necesidades básicas"ż. 
Según PREALC, la deuda social tiene dos componentes: la deuda social de largo plazo, y la deuda social de corto plazo. La deuda social de largo plazo "se refiere a los cambios distributivos necesarios para alcanzar un nivel de equidad socialmente aceptable y al costo de superar la pobreza total que existía antes de la coyuntura especifica, que será objeto de análisis"z'. En otras palabras, consiste en el monto de recursos que serían necesarios para producir los bienes y servicios que permitirian erradicar la pobreza históricamente acumulada.

El concepto convencional de "brecha de pobreza", el cual se refiere a la cantidad agregada de recursos - normalmente expresada como porcentaje del PIB - que habria que transferir a los pobres para que alcancen un nivel de ingreso medio que les permita situarse sobre la línea de pobreza ${ }^{28}$, ofrece una primera aproximación a la cuantificación de la deuda social de largo plazo, pero es insuficiente, porque no toma en cuenta el costo de generar dichos recursos. La superación de la pobreza no sólo cuesta la cantidad de recursos que actualmente les faltan a las familias pobres para llegar a la línea de pobreza, sino también la inversión necesaria para la generación de empleo y el aumento de la productividad de los pobres, de manera que se asegure un flujo permanente de ingresos que les permita la satisfacción de sus necesidades básicas, de tal manera que la pobreza quede erradicada. No se trata solamente de satisfacer las necesidades básicas de todos los pobres en un ano, sino de generar condiciones de empleo y productividad que posibiliten que esa satisfacción sea autosostenida. Lo mismo cabe decir de las transferencias de ingresos y la provisión de servicios sociales que el Estado hace a los pobres, y que constituyen un mecanismo complementario para erradicar la pobreza. Este mecanismo tiene también un costo de inversión y de funcionamiento, el cual incluye los insumos que se requieren, asi como los costos administrativos de los programas que proveen dichos servicios, e incluso la filtración de beneficios que suele darse en la ejecución de los programas ${ }^{20}$.

Asi, la deuda social de largo plazo equivaldria a la brecha de pobreza multiplicada por un factor que incluye el costo de generar y proveer esos recursos. Según PREALC, "una aproximación a este factor puede obtenerse estimando cuánto debió crecer el ingreso total y/o el de los grupos pobres para superar cada punto de incidencia en la pobreza"so. Para calcular el monto de la deuda social de largo plazo, PREALC tratar de estimar una elasticidad pobreza-ingreso de los pobres, expresada en términos del PIB ${ }^{31}$. En concreto, para el caso de América Latina, PREALC estima que, durante el periodo 1960-1977, en que la extensión de la pobreza disminuyó 18 por ciento, el ingreso de los pobres tuvo que aumentar en un monto equivalente al 15.8 por ciento del PIB, 
lo cual significó que la reducción de cada punto porcentual de extensión de la pobreza tuvo un costo de 0.88 por ciento del PIB. Asl, a la altura de 1977, el costo de la deuda social de largo plazo de América Latina equivalla a un 29 por ciento del PIB, si se considera que la extensión de la pobreza ascendla al 33 por ciento de la población, y so presupone que se mantenla el costo promedio de superar la pobreza del período 1960-1977 (0.88 del PIB por cada punto porcentual de reducción de la extensión de la pobreza).

Por su parte, la deuda social de corto plazo se refiere a la variación que la deuda social ha experimentado durante un perlodo determinado, por efecto de la implementación de ciertas medidas de política económica, y consiste en "el monto de recursos necesarios para evitar, por un lado, el aumento de la pobreza y, por el otro, proceder a restablecer en un marco equitativo la participación de los trabajadores no pobres en el ingreso"se. Para ello se necesita calcular: a) el monto de los recursos necesarios para que la "magnitud" de la pobreza vuelva al nivel que presentaba al comienzo del período de análisis; b) el monto de recursos necesarios para restablecer, en un marco equitativo y soclalmente aceptable, la proporción en que los sectores no pobres participaban en el ingreso a comienzos de dicho perlodo. En el caso concreto de PREALC, su interés principal es determinar cuánto ha aumentado la deuda social durante el periodo de ajuste estructural implementado por las economias latinoamericanas para hacerle frente a la crisis de la deuda externa. A tal efecto, PREALC distingue en la deuda social de corto plazo dos componentes principales: a) el costo de reducir la extensión e intensidad de la pobreza al nivel existente en el ano inicial del perlodo considerado ${ }^{33}$; b) el costo distributivo del ajuste, esto es, "la magnitud de la regresividad distributiva entre los no pobres, que haya ocurrido durante el periodo en cuestión'st.

La "magnitud" de la pobreza, a su vez, se origina en incrementos tanto de su "extensión" como de su "intensidad". La extensión de la pobreza no es otra cosa que la proporción entre el número de pobres y la población total ( $\mathrm{Np} / \mathrm{N})$; mientras que su intensidad expresa la divergencia entre la línea de pobreza y el ingreso medio de los pobres.

Según PREALC, el aumento de la extensión de la pobreza deriva fundamentalmente de la caída del ritmo de generación de empleo formal respecto del crecimiento de la oferta de trabajo, como consecuencia de la recesión económica, lo cual, a su vez, tiene tres efectos principales: a) un aumento del desempleo, que puede tener carácter clclico o estructural; b) un aumento del nivel de empleo de baja productividad en los sectores informal urbano (SIU) y tradicional rural (STR); y c) un 
aumento del número de personas que perciben salarios en el sector formal de la economia, que son inferiores a la línea de pobreza ${ }^{35}$.

Por su parte, el aumento de la intensidad de la pobreza ocurre fundamentalmente debido a una caida de los ingresos de los sectores más pobres, que puede tener tres causas principales: a) una disminución del gasto social por persona; b) una modificación en la composición del sector pobre, al aumentar el peso relativo de los desempleados y empleados de menores ingresos del sector informal, lo cual produce, a su vez, una caida del ingreso por persona de estos grupos; y c) una caida del ingreso medio del SIU-STR y/o de los salarios reales, lo cual induce una concentración de la distribución personal del ingre$\mathrm{so}^{36}$.

Para amortizar el incremento de la deuda social debido a la extensión de la pobreza, PREALC propone estimar, por un lado, el costo de generar empleos en actividades relativamente intensivas en el uso de mano de obra, con una remuneración salarial media equivalente al ingreso de necesidades básicas y, por otro, el monto de los recursos necesarios para incrementar la productividad del sector informal urbano ${ }^{37}$. Para amortizar el incremento derivado del aumento de la intensidad de la pobreza, PREALC calcula el monto de los ingresos que deberian transferirse en forma de servicios al sector pobre, asi como los costos administrativos y de insumos necesarios para la provisión de esos bienes y servicios.

Según el criterio de equidad distributiva, el costo del incremento total de la deuda social tendria que ser financiado por los sectores no pobres (trabajadores no pobres y capitalistas) de acuerdo a su participación en el ingreso previa a la crisis.

\subsection{Formalización del esquema analítico de la deuda soclal}

A partir de las precisiones conceptuales que anteceden, PREALC trata de formalizar una metodologia que permita cuantificar el monto de la deuda social ${ }^{38}$.

El punto de partida es, precisamente, la brecha de pobreza (Bp), la cual equivale al monto de recursos -expresado en términos del ingreso nacional $(Y)$ - que deberia adicionarse al ingreso de los sectores pobres (Np*yp) para que éstos alcancen el nivel de ingreso de satisfacción de necesidades básicas (Np"yb):

$$
B p=N p(y b-y p) / Y
$$


donde el ingreso nacional $(\mathrm{Y})$ es igual a la población total $(\mathrm{N})$ multiplicada por el ingreso per cápita (y):

$$
Y=N^{*} y
$$

Al sustituir (2) en (1), la brecha de pobreza queda definida en función de la extensión ( $N p / N)$ y de la intensidad (yb-yp/y) expresada en términos del ingreso per cápita:

$$
B p=(N p / N)[(y b-y p) / y]
$$

El ingreso medio de los pobres (yp) puede expresarse como una proporción del ingreso de necesidades básicas (yb):

$$
y p=\alpha y b
$$

donde $\alpha$ es el coeficiente que representa esa proporción. A su vez, el ingreso de necesidades básicas (yb) puede expresarse como una proporción del ingreso per cápita (y):

$$
y b=B y
$$

donde B representa esa proporción. Al sustituir (4) y (5) en (3), la brecha de pobreza queda definida en términos de su extensión ( $N p / N)$ y de los componentes de su intensidad ( $(\beta)$ y $(1-\alpha)$ :

$$
B p=(N p / N)[B(1-\alpha)]
$$

Tomando en cuenta los efectos de las variaciones de la composición del mercado de trabajo en la extensión de la pobreza, es preciso incluir en (6) dichas variaciones, que se dan al interior de la Población Económicamente Activa (PEA). A este respecto, PREALC define una tasa de participación ( $\delta$ ) de la fuerza de trabajo pobre (Fp) en relación al número total de pobres (Np):

$$
\delta=F p / N p
$$

as l como una tasa de participación $(\epsilon)$ de la PEA total sobre la población total:

$$
\epsilon=\text { PEAN }
$$


A su vez, la fuerza de trabajo del sector pobre (Fp) se distribuye entre los pobres ocupados en el sector moderno (Fpm), el sector informal (Fpi) y desocupados (Fpd):

$$
F p=F p m+F p i+F p d
$$

Al sustituir (7), (8) y (9) en (6), la extensión de la pobreza queda expresada en términos de la relación entre las tasas globales de participación $(\epsilon / \delta)$ y de la incidencia de los diferentes componentes de la fuerza de trabajo pobre en la PEA total:

$$
B p=(\epsilon / \delta)[(F p m+F p i+F p d) / P E A][B(1-\alpha)]
$$

Para evaluar en términos simplificados los componentes del crecimiento de la brecha de pobreza $\left(B^{\wedge}\right)$, PREALC supone que no varlan en el corto plazo: la relación entre las tasas globales de actividad $(\epsilon / \delta)^{\wedge}$; la proporción de trabajadores pobres del sector moderno en la PEA total (Fpm/PEA ${ }^{\wedge}$, ni la relación entre el ingreso de necesidades básicas y el ingreso per cápita $(B)^{\wedge}$ :

$$
\begin{aligned}
& (\epsilon / \delta))^{\wedge}=0 \\
& (\text { Fpm/PEA })^{\wedge}=0 \\
& B^{\wedge}=0
\end{aligned}
$$

Sobre el supuesto de (11), (12) y (13), PREALC senala que, en último término, el incremento de la extensión de la brecha de pobreza se origina en un aumento del grado de informalidad de la ocupación (Fpi PEA $)^{\wedge}$ y de la desocupación abierta $(\mathrm{Fpd} / \mathrm{PEA})^{\wedge}$ entre los pobres. Por su parte, la variación de la intensidad de la pobreza $(1-\alpha)^{\wedge}$ queda vinculada fundamentalmente a la reducción del ingreso de los pobres relativa al ingreso de necesidades básicas $(\alpha=y p / y b)$ :

$$
B p^{\wedge}=(F p i / P E A)^{\wedge}+(F p d / P E A)^{\wedge}+(1-\alpha)^{\wedge}
$$

Tomando en cuenta, según lo apuntado más arriba, que la deuda social de corto plazo con el sector pobre (Dsp) representa el monto de recursos necesarios, por un lado, para reducir la extensión de la pobreza a su nivel inicial $y$, por otro, para compensar mediante aumentos del gasto social el incremento de la intensidad de la pobreza, PREALC concluye, a partir de (14), que el incremento de la deuda social (Dsp^) equivale a una proporción del ingreso que es $k$ veces mayor que el 
requerido para cubrir la brecha de pobreza (Bp). Dicho multiplicador es función del costo de aumentar la productividad del sector informal (k1), de generar empleo (k2) y de reducir la intensidad de la pobreza a través del gasto social (k3):

$$
D s p^{\wedge}=k^{\wedge} B p^{\wedge}=k 1(F p i / P E A)^{\wedge}+k 2(F p d / P E A)^{\wedge}+k 3(1-\alpha)^{\wedge}
$$

Por tanto, el costo de la deuda social de corto plazo corresponde al porcentaje del producto que deberá destinarse para aumentar la productividad del sector informal (Dspi^), generar empleos con un salario semejante al de necesidades básicas para los desempleados (Dspd ${ }^{\wedge}$ ), y reducir al nivel original la intensidad de la pobreza $\left(\operatorname{Dspn}^{\wedge}\right)$ :

$$
D s p^{\wedge}=D s p i^{\wedge}+D s p d^{\wedge}+D s p n^{\wedge}
$$

El costo en términos del ingreso nacional de las pollticas para reducir la pobreza por la via de reducir la informalidad $(\sigma)$ y el desempleo abierto $(\theta)$, PREALC lo formaliza asi:

$$
\begin{aligned}
& \operatorname{Dspi}^{\wedge}=\sigma Y \\
& \operatorname{Dspd}^{\wedge}=\theta Y
\end{aligned}
$$

Para el caso de América Latina, PREALC estima que el monto de inversión necesaria para generar empleo corresponde al de actividades que tienen un coeficiente relativamente alto de salarios en el producto (0.5). Asimismo, considera que el salario medio sería igual al de necesidades básicas, el cual, como promedio para la región, representa un 25 por ciento del ingreso per cápita. Considerando una relación capitalproducto igual a la unidad, la cual justifica a partir de la capacidad ociosa existente, el costo de generar un uno por ciento adicional de empleo representa un 0.5 por ciento del PIB. Por tanto, el costo de la deuda social por concepto de incremento de extensión de la pobreza entre 1980-1985 (6 por ciento) equivaldría al 3 por ciento del PIB ${ }^{30}$.

Por otra parte, está también el costo del mayor gasto fiscal en términos del producto $(\Omega)$ :

$$
\mathrm{Dspn}^{\wedge}=\Omega Y
$$

Este costo tiene dos componentes: el costo de zanjar el aumento de la brecha de ingresos de los pobres respecto al ingreso de necesidades básicas $(1-\alpha)^{\wedge} ;$ y el costo tanto de insumos como de distribución de los 
bienes y servicios provistos por el gobiemo (f) de forma tal que $\Omega=$ (1$\alpha)^{\wedge}+f$. Para el periodo 1980-1985, PREALC estimó que $(1-\alpha)^{\wedge}=$ $0.9 \mathrm{PIB}$, mientras que $\mathrm{f}=0.6 \mathrm{PIB}$. Por tanto, $\Omega$ equivale a un 1.5 por ciento del PIB. En definitiva, asignando sus respectivos valores a (17), (18) y (19), resulta que el costo macroeconómico de la deuda social con el sector pobre $\left(\mathrm{Dsp}^{\wedge}=\mathrm{Dspi}^{\wedge}+\mathrm{Dspd}^{\wedge}+\mathrm{Dspn}^{\wedge}\right)$ en el período 1980-1985 ascendió a un 4.5 por ciento del PIB latinoamericano.

A este monto, sin embargo, todavía deben anadirse los costos que derivan del criterio de equidad distributiva en el pago de la deuda social, de modo que los trabajadores no pobres y los capitalistas contribuyan a financiarla de acuerdo a su participación en el ingreso previa a la crisis $^{40}$. Para medir este componente del costo de la deuda social (Dsnp^), PREALC formalizó el problema como sigue:

$$
Y^{\wedge}=a Y^{\wedge}+b Y^{\wedge}+c Y^{\wedge}
$$

donde el crecimiento del ingreso $\left(Y^{\wedge}\right)$ se distribuye entre los diferentes sectores sociales: sector pobre $\left(Y^{\wedge}\right)$, sector trabajador no pobre (Ytnp^) y capitalistas $\left(Y^{\wedge}\right)$. Por tanto, el ingreso disponible para los sectores no pobres (Ynp^) equivale al ingreso nacional menos el ingreso de los pobres, al cual se adiciona el pago de la deuda social $\left(Y p^{\wedge}+\right.$ Dsp^):

$$
Y n p^{\wedge}=Y^{\wedge}-\left(Y p^{\wedge}+D s p^{\wedge}\right)
$$

Queda por determinar la proporción en que el ingreso de los trabajadores no pobres y de los capitalistas se verá afectado con el pago de la deuda social. Básicamente, esta proporción sería la misma que imperaba al inicio de la crisis, aunque aplicada al nuevo ingreso disponible de los sectores no pobres $\left(Y \cap p^{\wedge}\right)$. Por tanto, el ingreso quedaría distribuido asi:

$$
Y^{\wedge}=a^{\prime} Y p^{\wedge}+b^{\wedge} Y \operatorname{tn} p^{\wedge}+c^{\prime} Y k^{\wedge}
$$

que expresa la distribución deseable del crecimiento económico $\left(Y^{\wedge}\right)$, donde a' refleja la mayor participación del sector pobre, en tanto b' y $c^{\prime}$ reflejan los cambios en las participaciones originales de los trabajadores no pobres y capitalistas. PREALC senala que, cuando la participación efectiva (b) de un grupo social (en este caso el de los trabajadores no pobres) en el ingreso sea menor que la indicada por la regla de equidistribución (b'), se generará una deuda social por inequidad distributiva (Dsnp^) con dicho grupo: 
En sintesis, según PREALC, el costo macroeconómico de la deuda social $\left(D s^{\wedge}\right)$ de corto plazo corresponde al monto de recursos en términos del PIB para superar el incremento de pobreza (kBp) más la fracción del ingreso necesaria para neutralizar la inequidad distributiva del ajuste $\left(b^{*}-b^{\prime}\right)$ :

$$
D s^{\wedge}=k B p+\left(b^{\bullet}-b^{\prime}\right) Y^{\wedge}
$$

\subsection{Estimación de la deuda soclal de corto plazo en El Salvador para el periodo 1989-1990}

A partir del esquema analítico esbozado en el apartado anterior, intentaremos ahora una estimación del monto de la deuda social que se ha generado en El Salvador durante el periodo 1989-1990.

Nuevamente, la estimación de esta variable enfrenta una grave limitación de principio: las Encuestas de Hogares de 1989 y 1990 solamente ofrecen datos sobre la pobreza urbana. Es obvio que, en tales condiciones, la estimación que pueda obtenerse subvalorará considerablemente la magnitud real de la deuda social, al dejar fuera del cálculo a los pobres rurales, quienes constituyen la mayoría de pobres y cuya pobreza es más intensa.

El Cuadro № 15 muestra la evolución de la pobreza urbana en EI Salvador para el periodo considerado, de acuerdo a los datos aportados por las Encuestas de Hogares de 1989-90. Según se aprecia, la extensión de la pobreza urbana aumentó de 34.3 a 36.9 por ciento (2.6 puntos porcentuales), lo cual significó, en términos absolutos, que 175,547 habitantes de las zonas urbanas del pais pasaron a engrosar las filas de los pobres.

Nótese que la brecha de la pobreza urbana, medida como porcentaje del PIB, se incrementó de 15 a 16.5 por ciento durante el mismo periodo. En términos absolutos, esto significa que, si en junio de 1989 se requerian 4,832 millones de colones para que el ingreso de los pobres urbanos se equiparara al ingreso que requerian para cubrir sus necesidades básicas, en junio de 1990, ese monto se habla incrementado a 6,702 millones de colones, esto es, habia aumentado en más de 1,800 millones de colones.

En lo que respecta al costo macroeconómico del incremento de la deuda social en dicho periodo, tenemos que, para reducir la extensión de la pobreza a su nivel de junio de 1989 (34.3 por ciento) se deberia Invertir un monto equivalente al $\mathbf{1 . 3}$ por ciento del PIB, el cual resulta 


\section{Cuadro N2 15 \\ Evoluclón de la pobreza urbana en El Salvador (1969-1990)}

\begin{tabular}{lcc}
\hline & 1989 & 1990 \\
\hline Número de pobres urbanos (Npu) & $1,760,898$ & $1,936,445$ \\
Población total (N) & $5,137,707$ & $5,251,678$ \\
$\begin{array}{l}\text { Extensión de la pobreza urbana } \\
\text { (Npu/N) }\end{array}$ & $34.3 \%$ & $36.9 \%$ \\
Brecha de pobreza urbana & $15 \%$ & $16.5 \%$ \\
\hline
\end{tabular}

Fuente: Elaboración propia en base a las Encuestas de Hogares de Propósitos Múltiples, Revistas del BCR e Indicadores Económicos y Sociales de MIPLAN.

- Porcentaje sobre el PIB.

de multiplicar el incremento de la extensión de la pobreza entre 19891990 (2.6 por ciento) por 0.5, que es el factor que PREALC estima necesario para generar un uno por ciento adicional de empleo de acuerdo a los supuestos arriba mencionados ${ }^{4}$. En términos absolutos, ello representa un monto de unos $\mathbf{5 3 0}$ millones de colones.

En cuanto al componente de intensidad de la pobreza, el cual aumentó de 43.7 a 44.7 por ciento entre 1989-1990, se ha estimado que, en junio de 1990, se necesitaba un monto de recursos equivalentes al 2.5 por ciento del PIB para reducir dicho componente a su nivel de junio de 1989. Esta cifra surge del monto de ingresos que habria que transferir en forma de servicios para que los nuevos pobres urbanos surgidos en dicho período alcanzaran la línea de pobreza, monto equivalente a un 1.5 por ciento del PIB; así como de los costos administrativos y de insumos necesarios para la provisión de esos bienes y servicios, que, manteniendo la metodologia de PREALC, habría que estimar en 1 por ciento del PIB42. En términos absolutos, el monto del componente de intensidad de la deuda social de corto plazo 19891990, ascendia a más de mil millones de colones.

Al agregar ambos componentes, resulta que la amortización del incremento de la deuda social con los pobres urbanos durante el período 1989-1990 requeriria asignar recursos equivalentes a un 3.8 por ciento del PIB, esto es, en términos absolutos, más de 1,500 millones de colones ${ }^{43}$.

De acuerdo a PREALC, el costo de dicha amortización tendria que ser sufragado por los sectores no pobres (trabajadores no pobres y ca- 
pitalistas) de acuerdo a un criterio equidistributivo. Para efectuar este cálculo, sin embargo, es menester conocer la distribución del ingreso nacional neto entre el sector pobre y los sectores no pobres, a partir de la distribución funcional del ingreso que arroja la matriz Insumo-producto. Desafortunadamente, para el caso de EI Salvador no se dispone de datos actualizados sobre la distribución funcional del ingreso, a nivel macroeconómico, entre remuneraciones y excedentes de explotación, lo cual impide calcular con un mínimo de precisión el costo distributivo de la deuda social ${ }^{\text {m. }}$.

\subsection{Estimación de la deuda soclal de largo plazo de El Salvador a la altura de 1990}

El procedimiento que PREALC emplea para calcular la deuda social de largo plazo es simple: consiste en multiplicar el nivel actual de extensión de la pobreza por un factor que representa el costo de reducir cada punto porcentual de esa extensión. PREALC calcula este factor a partir de lo que tiene que aumentar el ingreso anual de los pobres, medido como porcentaje del PIB, para que disminuya un punto porcentual la extensión de la pobreza. Por ejemplo, durante el perlodo 19601977, según apuntábamos más arriba, fue necesario que el ingreso de las familias pobres de América Latina aumentara en 0.88 por ciento del PIB para reducir cada punto porcentual de extensión de la pobreza. Para ello, el PIB latinoamericano tuvo que crecer a un ritmo promedio del 5.9 por ciento anual45. En 1977, la extensión de la pobreza en América Latina era del 33 por ciento. Multiplicando esta cifra por el factor mencionado (0.88), se obtendria la deuda social de largo plazo de América Latina en ese momento: 29 por ciento del PIB.

Para el caso de El Salvador, no es posible calcular el factor mencionado, que denominaremos $\mu$, de acuerdo al procedimiento empleado por PREALC. Simplemente, se carece de los datos estadisticos necesarios para seguir la evolución del ingreso de los pobres en un período prolongado (una década o más), de modo que pueda calcularse cuánto ha debido aumentar su ingreso para que la extensión de la pobreza disminuya en cada punto porcentual.

Para el cálculo de la deuda social de largo plazo, pues, no nos queda, de momento, más recurso que asumir para $\mu$ el valor que PREALC le asigna (0.88). Esto implica que, en 1990, el costo de reducir a cero la extensión de la pobreza urbana (36.9 por ciento) equivalia al 32.5 por ciento del PIB, lo cual, traducido a términos absolutos, ascendla a más de 13,200 millones de colones. Es pertinente enfatizar de nuevo que este monto se refiere únicamente a la deuda social de largo plazo 
contraida con los pobres urbanos. Obviamente, el monto de la deuda social de largo plazo total sería mucho mayor, según puede proyectarse a partir de la distribución geográfica de la pobreza según las Encuestas de Hogares de Propósitos Múltiples de 1985.

\section{Cuadro N2 16}

Estructura de la pobreza en El Salvador en 1977 y 1985

\begin{tabular}{crc}
\hline & \multicolumn{2}{c}{ Nümero de familia } \\
& 1977 & 1985 \\
\hline $\begin{array}{c}\text { Pobreza Extrema } \\
\text { Urbana }\end{array}$ & 35,812 & 150,063 \\
Rural & 218,390 & 267,828 \\
Total & 254,202 & 417,891 \\
Pobreza Relativa & & \\
Urbana & 216,715 & 273,342 \\
Rural & 200,974 & 160,698 \\
Total & 417,689 & 434,040 \\
Pobreza Total & 671,891 & 851,931 \\
Total de familias & 798,206 & 946,592 \\
Urbanas & 361,151 & 500,210 \\
Rurales & 437,055 & 446,382 \\
\hline
\end{tabular}

Fuente: Encuestas de Hogares de Propósitos Mültiples de 1977 y 1985.

Según las Encuestas de Hogares de 1985, ese ano habia 851,931 familias situadas bajo la línea de pobreza, de las cuales 423,405 (49.7 por ciento) pertenecian al área urbana y 428,526 (50.3 por ciento) al área rural (Cuadro № 16). Del total de familias pobres, 417,891 (49 por ciento) estaban en situación de pobreza extrema, y las restantes 434,040 (51 por ciento) en situación de pobreza relativa. Sobre el total de familias en pobreza extrema, 150,063 (36 por ciento) pertenecian al área urbana, y 267,828 (64 por ciento) al área rural. Por su parte, sobre el total de familias en pobreza relativa, 273,342 (63 por ciento) penenecian al área ubana y 160,698 (37 por ciento) al área rural. Estos datos sugieren una considerable concentración de la pobreza extrema en las zonas rurales y de la pobreza relativa en las zonas urbanas.

Si se acepta que, en lo fundamental, esta estructura de distribución de la pobreza entre las áreas urbanas y las zonas rurales no ha varia- 
do significativamente entre 1985-1990, entonces por lo menos la mitad de los pobres de El Salvador estaban en el campo en 1990. El Cuadro $N^{*} 17$ presenta una estimación de la evolución de la pobreza total para el periodo 1989-1990, desagregando la pobreza rural y urbana a partir de las proyecciones que permite la distribución geográfica de la pobreza de las Encuestas de Hogares de 1985. Según este cuadro, la extensión de la pobreza en el país habria aumentado de 69 a 74 por ciento (5 puntos porcentuales) entre 1989 y 1990. Un estimado de la deuda social de largo plazo total (contraida con todos los pobres) ascenderia, por tanto, a más de 26 mil millones de colones (a precios corrientes), sobre el supuesto de que la intensidad de la pobreza fuese similar en el campo que en la ciudad. Pero este supuesto es muy discutible, como lo muestra el grado de concentración de la extrema pobreza en las zonas rurales: en 1985, el 62.5 por ciento de los pobres rurales estaba en situación de pobreza extrema.

Cuadro № 17

Estimación de la evolución de la pobreza en El Salvador (1969-1990

\begin{tabular}{ccc}
\hline & 1989 & 1990 \\
\hline Número de pobres (Np) & $3,543,054$ & $3,896,258$ \\
Urbanos' $^{\prime}$ & $1,760,898$ & $1,936,445$ \\
Rurales $^{1}$ & $1,782,156$ & $1,959,823$ \\
Población total (N) & $5,137,707$ & $5,251,678$ \\
Extensión de la Pobreza (Np/N) & $69 \%$ & $74 \%$ \\
Brecha de Pobreza & $\%$ & $33.15 \%$ \\
\hline
\end{tabular}

Fuente: Elaboración propia a partir de las Encuestas de Hogares y de las revistas del BCR.

1 Estimación a partir de la estructura de la distribución geográfica de la pobreza on 1985.

ข Calculada como porcentaje del PIB.

Para obtener una cifra más precisa del monto de la deuda social de largo plazo contraida con todos los pobres (urbanos y rurales), habria que incorporar a los cálculos ese factor-intensidad de la pobreza, que PREALC no desarrolla analíticamente. 


\subsection{El desafio del pago de la deuda soclal}

¿Qué capacidad tiene el Plan de Desarrollo Social 1990-1994 del gobierno de ARENA para hacer frente a esta ingente deuda social acumulada históricamente?

Si nos atenemos al plan de inversiones públicas contenido en el Plan de Desarrollo Económico y Social (Ver Cuadro Ne 18), el gobierno ha programado para el quinquenio 1990-1994 una inversión en el área social por un monto de 6,303.3 millones de colones, de los cuales 2,563.3 millones corresponderían a inversión en infraestructura social y 3,470 millones a inversion en capital humano. Esta última estaría dirigida a programas de salud y nutrición para reducir la mortalidad infantil y elevar la calidad de los servicios; programas de educación vocacional; programas de asistencia a las comunidades urbanas y rurales; programas de capacitación para los pequehos agricultores, etc. ${ }^{46}$.

\section{Cuadro Ne 18}

Gasto soclal quinquenio 1990 - 1994

A preclos de 1990

(Millones de colones)

\begin{tabular}{|c|c|c|c|c|c|c|}
\hline & $\begin{array}{c}D+C \\
\text { Gasto total } \\
\text { Valor }\end{array}$ & $(\%)$ & $\begin{array}{l}\text { D } \\
\text { Inversión } \\
\text { física* }\end{array}$ & $\begin{array}{l}(C=A+B) \\
\text { Inversión } \\
\text { sub-total }\end{array}$ & $\begin{array}{c}\text { (A) } \\
\text { Recursos } \\
\text { humanos } \\
\text { AID }\end{array}$ & PMA \\
\hline Educación & 1.346 .6 & 21.5 & 1.071 .9 & 282.7 & 282.7 & 0.0 \\
\hline Salud & 1.751 .2 & 27.8 & 499.3 & 1.251 .9 & 1.251 .9 & 0.0 \\
\hline $\begin{array}{l}\text { Asistencia social } \\
\text { Trabajo y pre- }\end{array}$ & 239.7 & 3.8 & 39.5 & 200.2 & 200.2 & 0.0 \\
\hline vención social & 379.5 & $6: 0$ & 126.0 & 253.5 & 253.5 & 0.0 \\
\hline Vivienda & 486.8 & 7.7 & 486.8 & 0.0 & 0.0 & 0.0 \\
\hline $\begin{array}{l}\text { Alimentos } \\
\text { Desarrollo urba- }\end{array}$ & 455.0 & 7.2 & 0.0 & 455.0 & 0.0 & 455.0 \\
\hline $\begin{array}{l}\text { no y comunal } \\
\text { Capacitación }\end{array}$ & 437.5 & 6.9 & 340.0 & 97.5 & 97.5 & 0.0 \\
\hline campesina & 1.199 .2 & 19.0 & 0.0 & 1.199 .2 & 1.199 .2 & 0.0 \\
\hline $\begin{array}{l}\text { Total } \\
\%\end{array}$ & $\begin{array}{r}6.303 .5 \\
100 \%\end{array}$ & $100 \%$ & $\begin{array}{r}2.563 .5 \\
40.7\end{array}$ & $\begin{array}{r}3.740 .0 \\
59.3\end{array}$ & 3.285 .0 & 455.0 \\
\hline
\end{tabular}

Fuente: Dirección General de proyectos; Grupo Asesor Económico y Social, MIPLAN

- Este gasto forma parte del plan quinquenal e inversiones publicas. 
Si aceptamos la estimación de una deuda social de largo plazo superior a los 26 mil millones de colones, resulta evidente que todo el plan de gastos sociales gubernamentales programado para el quinquenio 1990-1994 no puede servir, en el mejor de los casos, sino de paliativo para resolver el problema de la pobreza estructural. $Y$ ello en el supuesto de que la inversión programada se lleve a cabo efectivamente, lo cual resulta dudoso si se considera que, todavla a mediados de 1990, a un ano de haber iniciado ARENA la implementación de su programa de estabilización, los recursos para la inversión en capital humano, los cuales serian proporcionados principalmente por la AID y por el Programa Mundial de Alimentos (PMA), estaban todavia en proceso de negociación, mientras que para la inversión en infraestructura social sólo se tenian contratados $\mathbf{3 1 5 . 2}$ millones de colones (los resantes 2,248.1 millones aún tenian que ser gestionados). En concreto, después de un ano de gestión, el gobierno de El Salvador disponla efectivamente sólo de 315.2 millones de colones para hacerle frente a una deuda social de más de 26 mil millones de colones.

El problema se agrava en la medida que ni siquiera los mecanismos contemplados en el Plan de Desarrollo Social han funcionado de acuerdo a lo programado. Asi, el Plan se proponla constituir en el corto plazo un Fondo de Inversión Social (FIS), "que desarrolle funciones de captación de recursos financieros nacionales e internacionales, que canalice dichos recursos hacia áreas productivas a pequena escala y áreas sociales prioritarias; y que supervise la ejecución de los proyectos a desarrollarse en las diferentes regiones del pals ${ }^{47}$. No obstante, a la altura de septiembre de 1990, el FIS disponla únicamente de 6 millones de los 300 millones de colones que requiere anualmente para ope$\mathrm{rar}^{20}$. Obviamente, el Plan de Desarrollo Social de ARENA estaba virtualmente incapacitado para hacer frente al desaflo de la deuda social de largo plazo, e incluso a la de corto plazo.

\section{A modo de conclusión}

La cuantificación de una canasta básica de bienes y servicios para el área urbana, seguida en su evolución a lo largo del periodo junio 1989-noviembre 1990, refleja una sensible profundización de la pobreza urbana en EI Salvador durante ese período, el cual corresponde a la primera etapa del Plan de Desarrollo Económico y Social 1989-1994 del gobierno de ARENA.

De acuerdo al diagnóstico del Plan, esa profundización de la pobreza se habrla debido a diversos factores exógenos al programa económico del gobierno, tales como la "agresión terrorista", el legado "Inter- 
vencionista" de la Democracia Cristiana, "condiciones extemas adver sas" $^{n}$, etc. ${ }^{49}$ Nosotros, en cambio, si bien no negarnos el influjo de esos factores como variables intervinientes que han contribuido a acentuar el deterioro de las condiciones de vida de los sectores populares en el periodo 1989-1990, consideramos que dicho deterioro se ha debido fundamentalmente al sesgo recesivo del conjunto de pollticas de estabilización contempladas en el Plan de Desarrollo Económico y Social 1989-1994, las cuales, al inducir un efecto contractivo sobre la demanda, han propiciado el deterioro de los niveles de empleo y de los ingresos reales de la mayoria de la población y, por tanto, de las posibilidades de satisfacción de las necesidades básicas, sobre todo de los grupos sociales que viven en situación de pobreza y de pobreza extrema. Aunque, en rigor, no hemos intentado desarrollar esta tesis en el presente trabajo, lo cual hubiera rebasado con creces las dimensiones del mismo, consideramos que seria una hipótesis que habrla que retomar al momento de intentar analizar los principales factores causales que explican tal situación.

Nuestro análisis se ha cenido a la etapa de la estrategia de corto plazo del Plan, esto es, al periodo de implementación de las pollticas de estabilización. Consideramos que a estas alturas, serla prematuro formular predicciones sobre el éxito del programa de ajuste en el mediano plazo en términos estrictamente económicos. Con todo, es posible anticipar ciertas tendencias en materia social tomando en cuenta la indole de la estrategia socio-económica adoptada por el gobiemo de ARENA.

Cientamente, el Plan posee una conciencia bastante expllcita de la gravedad de las deficiencias prevalecientes en el pals en materia de satisfacción de las necesidades básicas, sobre todo de los sectores poblacionales más vulnerables. En particular, es de resaltar que, pese a su concepción esencialmente neoliberal de la economia, ARENA admite que el crecimiento económico no genera per se desarrollo social y que, por tanto, las políticas económicas de estabilización no lograrán automáticamente satisfacer las necesidades básicas de los grupos de población más vulnerables, los cuales requieren de una política social ad hoc. Con todo, en su concepción doctrinaria del ajuste estructural de la economia, el Plan retoma varias de las medidas convencionales de reducción de la demanda al uso en los programas ortodoxos del ajuste (restricciones de la oferta monetaria, reducción del gasto público, etc.) $y$, sobre todo, el tipo de reformas institucionales aconsejadas por el neoliberalismo económico, tales como la liberalización del comercio exterior, liberalización de precios, privatización del aparato productivo, etc. Asimismo, asume con total convicción el supuesto de que el sector 
privado es siempre mejor administrador y productor que el Estado y que sólo cuando la economía funcione en manos privadas podrá alcanzar su productividad óptima.

El resultado de ello es que, al momento de traducir su concepción doctrinaria de la problemática social en medidas concretas de política económica, el Plan parece descuidar las mesoimplicaciones que las macropolíticas de estabilización tienen sobre los sectores más vulnerables de la población $n^{50}$. La lógica misma del modelo económico propuesto, más orientado a reactivar la economía por la via de su apertura al exterior que por el fortalecimiento del mercado intemo, no parece ser la idónea para enfrentar la grave problemática social del país. A final de cuentas, pareciera que lo que se persigue no es mejorar el nivel de vida de la población o erradicar la pobreza, sino fortalecer los mecanismos de mercado. Es significativo que entre las primeras medidas de política económica que entraron en vigencia en julio de 1989, al iniciarse formalmente la implementación de la estrategia económica de corto plazo del Plan, figurara una liberalización virtualmente general de precios. Ello implicará que, a la postre, sean los sectores sociales más vulnerables quienes carguen con los mayores costos de la estabilización, como parece mostrarto el sensible deterioro experimentado por la satisfacción de las necesidades básicas de los grupos sociales más vulnerables durante 1989-1990.

Tal como lo hemos apuntado más arriba, por limitaciones de información estadistica, nuestro análisis se ha cenido al área urbana, lo cual arroja una notable subestimación de la magnitud real del deterioro de las condiciones de vida de los gnupos sociales vulnerables y, en definitiva, de la magnitud en que se ha profundizado la pobreza durante el período considerado. Las Encuestas de Hogares de Propósitos Múltiples de 1989 y 1990 dejan por fuera a toda la población rural, que es presumiblemente donde la pobreza está más difundida y es más intensa. Aparte de las Encuestas de Hogares, virtualmente no hay otras fuentes que arrojen información actualizada sobre la situación de las necesidades básicas durante 1989-1990.

Aunque el gobierno asegura que la economía creció 3.4 por ciento en términos reales en 1990, esa presunta expansión no fue suficiente para absober el incremento de la PEA ubana entre 1989-1990, la cual creció en 14 por ciento ${ }^{51}$. Como resultado de ello, los ingresos reales de los sectores sociales que viven en situación de pobreza y pobreza extrema experimentaron un sensible deterioro, y la satisfacción de sus necesidades básicas se tomó aún más crítica. De hecho, las proplas Encuestas de Hogares de MIPLAN muestran que, entre 1989 y 1990. 
otras 45,683 familias $(207,400$ personas) se anadieron a los hogares urbanos que se encontraban en situación de extrema pobreza a comienzos de 1989. En el mismo período, los hogares ubanos en situación de pobreza relativa aumentaron en 11,563 familias (52,496 personas). En total, los hogares urbanos situados bajo la línea de pobreza aumentaron en 57,246 familias (259,897 personas) entre 1989 y $1990^{52}$.

De acuerdo al gobierno, la dramática situación por la que atraviesan los sectores sociales situados por debajo de la línea de pobreza empezaría a resolverse de modo más efectivo en la medida que las políticas de estabilización logren restablecer el equilibrio de las principales variables macroeconómicas, empiecen a generarse mayores puestos de trabajo y mejoren los niveles de ingresos reales, con el consiguiente mejoramiento de la satisfacción de las necesidades básicas.

Mientras tanto, la evidencia empírica disponible indica que los costos económicos de la estabilización no han sido distribuidos equitativamente, sino que han recaido primordialmente sobre aquellos sectores sociales cuyos ingresos provienen de su trabajo, de modo que sus condiciones de vida se han deteriorado más rápido que los del resto de la sociedad. Sin duda, la estabilización ha afectado también a los sectores no pobres, pero de manera menos crítica. Claramente, el sobrecosto de la estabilización lo están pagado los asalariados, subempleados y desempleados.

\section{ANEXO: CALCULOS}

1. Cálculo de la brecha de pobreza urbana (Bpu).

De acuerdo a la ecuación (3) del apartado 3.2, tenemos que:

$B p=(N p / N)\left[\left(y_{0}-y_{p}\right) / y\right]$

Los valores para las variables respectivas de la ecuación (3), correspondientes a 1989 y 1990, son los siguientes:

$\mathrm{Npu}_{\theta \theta}=1,760,898$ personas

$\mathrm{Npu}_{\infty}=1,936,445$ personas

$N_{60}=5,137,707$ personas

$N_{\infty}=5,251,678$ personas

$y_{b 89}=1,891.95$ colones (familiar mensual); 416.73 colones (per capita)

$y_{b 00}=2,258.67$ colones (familiar mensual); 497.50 colones (per capita)

$y_{p B O}=853.72$ colones (familiar mensual); 188.04 colones (per capita)

$\mathrm{yP}_{\mathrm{so}}=949.77$ colones (familiar mensual); 209.20 colones (per capita) 
$y_{80}=523.37$ colones

$y_{\infty}=645.52$ colones

Para la obtención del número de pobres urbanos (Npu) partimos de una línea de pobreza dada por el ingreso de necesidades básicas para el área urbana (yb), el cual consideramos equivalente al costo de la canasta ampliada de bienes y servicios básicos para una familia salvadoreha urbana promedio (Cuadro $N^{2} 13$ ). Para junio de 1989, esa canasta tenla un costo mensual de 1,891.95 colones por familia; para junio de 1990, se habia incrementado a 2,258.67 colones. Dividiendo entre 4.54 (número promedio de integrantes por familia urbana), obtenemos el ingreso de necesidades básicas per capita: 416.73 (junio 1989) y 497.50 (junio 1990).

Conociendo la línea de pobreza, obtenemos del Cuadro $N^{2} 14$, por extrapolación lineal, el número de familias pobres urbanas (Fpu) como porcentaje del total de hogares urbanos:

$\mathrm{FP}_{\mathrm{BO}}=78 \%$

$\mathrm{FP}_{\infty}=81 \%$

Traduciendo estos porcentajes en términos absolutos, y multiplicando por 4.54, obtenemos el número de pobres urbanos:

Npu89 $=1,760,898$ personas

$\mathrm{Npu90}=1,936,445$ personas

El ingreso per capita (y) surge de la ecuación (2). Consideramos el ingreso nacional $(\mathrm{Y})$ como equivalente al PIB por un convencionalismo metodológico, debido a que algunos factores que más adelante ocuparemos para el cálculo de la deuda social, y que tomamos de PREALC, están referidos al PIB. Asi, tenemos que:

$\mathrm{PIB}_{80}=3.2267 \times 1010$ colones

$\mathrm{PIB}_{\infty}=4.0681 \times 1010$ colones

Considerando que $y=P I B / N$ (por modificación de la ecuación 2), tenemos que:

$y_{80}=6,280.43$ colones (anual); 523.37 colones (mensual)

$y_{\infty 0}=7,746.29$ colones (anual); 645.52 colones (mensual)

Aplicando los valores correspondientes a la ecuación (3), obtenemos: 
$\mathrm{BpU}_{\mathrm{BO}}=15 \%$ (como porcentaje del PIB)

$B \mathrm{Bu}_{\infty}=16.5 \%$ (como porcentaje del PIB)

2. Calculo de la deuda soclal de corto plazo (DSCP) con los pobres ubanos, para el periodo 1989-1990.

De acuerdo a la metodologla de PREALC, la deuda social de corto plazo tiene dos componentes: por variación de la extensión de la pobreza y por variación de su intensidad.

\subsection{Incremento de la DSCP por varlación de la extensión de la po- breza urbana.}

De acuerdo al Cuadro $N^{2} 15$, tenemos que entre 1989 y 1990, la extensión de la pobreza urbana aumentó de $34.3 \%$ a $36.9 \%$, esto es, 2.6 puntos porcentuales. Según to apuntado en el apartado 3.3, PREALC estima en 0.5 el factor necesario para generar un uno por ciento adicional de empleo de tal manera que se revierta cada punto porcentual de extensión de la pobreza. Multiplicando $2.6 \%$ por 0.5 , tenemos $1.3 \%$ (como porcentaje del PIB), lo cual representa el costo macroeconómico del incremento de la deuda social entre 1989-1990 por concepto de extensión de la pobreza urbana.

\subsection{Incremento de la DSCP por varlación de la Intensidad de la pobreza urbana.}

La intensidad [(yb-yp)/y] de la pobreza urbana aumentó de $43.7 \%$ a 44.7\% entre 1989-1990. Para calcular el costo de la deuda social de corto plazo por la variación de este componente, habria que estimar el monto de ingresos que habria que transferir a los nuevos pobres urbanos surgidos en dicho periodo para que éstos alcanzaran la línea de pobreza:

$\left(\mathrm{Npu}_{90}-\mathrm{Npu}_{89}\right)\left(\mathrm{yb}_{90}-\mathrm{yP}_{90}\right)(12$ meses $)=6.073224 \times 10^{8}$ colones

(1.5\% PIB)

De acuerdo a la metodologia de PREALC, la provisión de los bienes necesarios para que esos nuevos pobres urbanos alcancen la línea de pobreza tiene un costo de insumos y administrativo que mantiene una proporción de 1 a 1.5 respecto del costo de dichos bienes. Por tanto, en este caso, equivale al 1\% del PIB (en téminos absolutos, 407 millones de colones). En total, el incremento de la DSCP 1989-1990 por variación de la intensidad de la pobreza urbana equivaldría a $2.5 \%$ del PIB, esto es, en términos absolutos, 1014 millones de colones. 


\section{Cálculo de la deuda soclal de largo plazo (DSLP).}

Para el cálculo de la deuda social de largo plazo, por las razones apuntadas en el apartado 3.4, no nos queda más recurso que asumir el valor que PREALC obtiene para el factor $\mu(0.88)$, el cual habrla que multiplicar por la extension de la pobreza. Asl, tenemos que para 1990 la extensión de la pobreza urbana ascendla a 36.9\% (Cuadro № 15). Por tanto, la deuda social de largo plazo con los pobres urbanos a esa fecha era:

$(36.9 \%)(0.88)=32.5 \% \mathrm{PIB}=1.3209934 \times 10^{10}$ colones

Por to que respecta a la deuda social de largo plazo total, esto es, la contralda con todos los pobres (urbanos y rurales), tenemos que en 1990, la extensión de la pobreza total, de acuerdo a los supuestos con que fue elaborado el Cuadro $N^{2} 17$, ascendla a $74 \%$. Por tanto, el monto de la deuda social de largo plazo total a esa fecha era:

$(74 \%)(0.88)=65.12 \% \mathrm{PIB}=2.6491467 \times 10^{10}$ colones

\section{Notas}

1. Ministerio de Planificación y Coordinación del Desarrollo Económico y Social. Plan de Desarrollo Económico y Social 1989-1994. El Salvador, 1989, p. I.

2. Ibid., p. 16.

3. Ibid., p.16.

4. Ibid., p. 56.

5. Ibid., p. 56.

6. Ibid., p. 13.

7. Ibid., p. 67. Según el Plan, esta situación serla consecuencia de: 1) "pollticas económicas erradas"; 2) un "sistema enmarañado de controles de precios" $^{\prime \prime}$ intervención estatal en la función productiva; y 3) el conflicto bélico.

8. Ibid., p. 67.

9. Ibid., p. 67.

10. Estimaciones del Banco Central de Reserva (BCR). Diario El Mundo, 4 de marzo de 1991, p. 6.

11. Sobre la importancia de la oportunidad y actualidad de la información estadistica, ct. Frances Stewart, "Seguimiento e información estadística del ajuste con rostro humano", en Giovanni Andrea Cornia, Richard Jolly y Frances Stewart (Comps.). Ajuste con rostro humano. Vol. 1. Madrid: Siglo $X X I, 1987$, pp. 327-338.

12. SECONAN, La canasta básica de alimentos como instrumento de la planificación alimentaria-nutricional. San Salvador, diciembre de 1986, p. 1.

13. Fernández Peredo, Froilán. Determinación del consumo minimo en El Sal- 
vador. Ministerio de Trabajo y Previsión Social. San Salvador, septiembre de 1979.

14. Ibid., p. 2.

15. El costo normativo de vestuario del Cuadro № 6 está calculado a partir de una familia integrada por 5 miembros. A efecto de homogenizar los cálculos entre la canasta ampliada y la canasta alimentaria, en el Cuadro № 7 asumimos una familia de 4.54 miembros.

16. Ibid., p. 31.

17. Dicho Acuerdo modificó las tarifas de venta de energla eléctrica a partir del 1 de noviembre de 1987.

18. Cf. Carlos Briones, "Realidad y perspectivas de la pobreza en El Salvador", Boletín de Ciencias Económicas y Sociales, Noviembre-diciembre de 1987, pp. 428-429; Oscar Altimir, "La pobreza on América Latina. Un examen de conceptos y datos". Revista de la CEPAL, № 13. Santiago de Chile, abril de 1981, p. 67; PNUD-OIT, La pobreza en el área metropolitana de San Salvador, 1988, pp. 1-7; Banco Mundial, Informe sobre el desarrollo mundial 1990, p. 29.

19. Cf. MIPLAN, Encuesta de Hogares de Propósitos Múltiples, 1989, Vol. I, p. 41; PNUD-OIT, op. cit., p. 6.

20. Cf. Las Encuestas de Hogares de Propósitos Múltiples, 1989-1990.

21. PREALC, Deuda social: esquema de diagnóstico y de recuperación, Documento de trabajo No 343. Santiago de Chile, febrero de 1990, p. 2.

22. PREALC, Ajuste y deuda social. Un enfoque estructural. Santiago de Chile, 1987.

23. PREALC, Deuda social: ¿qué es, cuánto es, cómo se paga? Santiago de Chile, 1988.

24. Ibid., p. 2.

25. Ibid., p. 2.

26. Ibid., p. 5.

27. Ibid., p. 9.

28. Cf. Oscar Altimir, op. cit.; Sergio Molina, "La pobreza. Descripción y análisis de políticas para superarla", Revista de la CEPAL, Santiago de Chile, diciembre de 1982.

29. PREALC, op. cit., pp. 12-13.

30. Ibid., pp. 9-10.

31. Ibid., p. 14.

32. Ibid., p. 95.

33. En el caso del análisis de PREALC, el inicio de la década de los ochentas.

34. Ibid., p. 17.

35. Ibid., pp. 17-18.

36. Ibid., p. 18.

37. Ibid., p. 34.

38. La nomenclatura que seguimos de acá en adelante no es en todos los casos la misma que propone PREALC. Con todo, hemos respetado la lógica de su formalización.

39. Ibid., p. 101. 
40. En este caso, 1980.

41. Ibid., p. 101.

42. Ibid., p. 102.

43. Un método más preciso para efectuar este cálculo tendría que recurrir a las ecuaciones de la (14) a la (19) del apartado 3.2. No obstante, las Encuestas de Hogares de 1989 y 1990 no aportan los datos necesarios para efectuar dichos cálculos.

44. De acuerdo a la matriz insumo-producto elaborada por el BCR para 1978, en dicho año las remuneraciones representaban el 35\% del valor agregado de la economía salvadoreña y el $40.5 \%$ de la renta de factores internos, mientras que los excedentes de explotación representaban el $54 \%$ y el $59.5 \%$, respectivamente, lo cual refleja una concentración muy alta del ingreso nacional. Cf. Banco Central de Reserva, Matriz Insumo-producto de 1978 de la economía salvadoreña. San Salvador, 1986; PNUD-OIT, Ingresos y salarios en El Salvador, 1988, p. 1.

45. Ibid., p. 16.

46. Plan de Desarrollo Económico y Social 1989-1994, p. 79.

47. Ibid., p. 62.

48. Cf. la ponencia de Roberto Murray Meza, presidente del consejo de administración del FIS, presentada ante el seminario internacional sobre "Estrategias para la erradicación de la pobreza en Centroamérica". San Salvador, septiembre de 1990.

49. Ibid., p. I.

50. Cf. Frances Stewart, "Macropoliticas y mesopoliticas alternativas y grupos vulnerables", en G. Andrea Cornia, et al., Op. cit., pp. 183-205.

51. El diferencial entre este 14 por ciento y el 12 por ciento al que creció la población urbana ocupada, se tradujo en un aumento del 1.6 por ciento de la tasa de desocupación abierta, la cual se incrementó de 8.4 a 10 por ciento, mientras que la tasa de subocupación aumentó levemente de 48.2 a 48.9 por ciento. Cf. Encuestas de Hogares de Propósitos Múltiples de 1989 y 1990. A la vez, el número de cesantes urbanos aumentó en 47.3 por ciento, pese al objetivo explicito de generar empleos perseguido por varios de los programas compensatorios contemplados en la estrategia de corto plazo del Plan de Desarrollo Social.

52. Encuestas de Hogares de Propósitos Múltiples, 1989-1990. 